\title{
Integrative Structural and Computational Biology of Phytases for the Animal Feed Industry
}

\author{
Nima Ghahremani Nezhad ${ }^{1,2}$, Raja Noor Zaliha Raja Abd Rahman 1,3(D), Yahaya M. Normi ${ }^{1,2}$, \\ Siti Nurbaya Oslan ${ }^{1,4}$, Fairolniza Mohd Shariff ${ }^{1,3}$ and Thean Chor Leow $1,2,5, *$ (i) \\ 1 Enzyme and Microbial Research Center, Faculty of Biotechnology and Biomolecular Sciences, Universiti \\ Putra Malaysia, UPM Serdang, Selangor 43400, Malaysia; gs52916@student.upm.edu.my (N.G.N.); \\ rnzaliha@upm.edu.my (R.N.Z.R.A.R.); normi_yahaya@upm.edu.my (Y.M.N.); \\ snurbayaoslan@upm.edu.my (S.N.O.); fairolniza@upm.edu.my (F.M.S.) \\ 2 Department of Cell and Molecular Biology, Faculty of Biotechnology and Biomolecular Sciences, \\ Universiti Putra Malaysia, UPM Serdang, Selangor 43400, Malaysia \\ 3 Department of Microbiology, Faculty of Biotechnology and Biomolecular Sciences, Universiti Putra Malaysia, \\ UPM Serdang, Selangor 43400, Malaysia \\ 4 Department of Biochemistry, Faculty of Biotechnology and Biomolecular Sciences, Universiti Putra Malaysia, \\ UPM Serdang, Selangor 43400, Malaysia \\ 5 Institute of Bioscience, Universiti Putra Malaysia, UPM Serdang, Selangor 43400, Malaysia \\ * Correspondence: adamleow@upm.edu.my
}

Received: 26 May 2020; Accepted: 29 June 2020; Published: 28 July 2020

check for updates

\begin{abstract}
Resistance to high temperature, acidic $\mathrm{pH}$ and proteolytic degradation during the pelleting process and in the digestive tract are important features of phytases as animal feed. The integration of insights from structural and in silico analyses into factors affecting thermostability, acid stability, proteolytic stability, catalytic efficiency and specific activity, as well as N-glycosylation, could improve the limitations of marginal stable biocatalysts with trade-offs between stability and activity. Synergistic mutations give additional benefits to single substitutions. Rigidifying the flexible loops or inter-molecular interactions by reinforcing non-bonded interactions or disulfide bonds, based on structural and roof mean square fluctuation (RMSF) analyses, are contributing factors to thermostability. Acid stability is normally achieved by targeting the vicinity residue at the active site or at the neighboring active site loop or the pocket edge adjacent to the active site. Extending the positively charged surface, altering protease cleavage sites and reducing the affinity of protease towards phytase are among the reported contributing factors to improving proteolytic stability. Remodeling the active site and removing steric hindrance could enhance phytase activity. $\mathrm{N}$-glycosylation conferred improved thermostability, proteases degradation and $\mathrm{pH}$ activity. Hence, the integration of structural and computational biology paves the way to phytase tailoring to overcome the limitations of marginally stable phytases to be used in animal feeds.
\end{abstract}

Keywords: thermostability; acid stability; proteolytic stability; improved activity; microbial phytases

\section{Introduction}

Phytic acid is the principal storage and indigestible organic form of phosphorous, accounting for up to $85 \%$ of the total phosphorous in plant seeds [1]. Phytase (myo-inositol hexakisphosphate phosphohydrolase) is an enzyme that catalyzes the hydrolysis of phytic acid (myo-inositol hexakisphosphate) through the stepwise approach to produce inorganic phosphate. Phytase is usually used in monogastric animal diets as a feed additive to boost phosphorus nutrition from their feed that is supplied from seeds, legumes, nuts, and grains. Besides, phytate can also form complexes with carbohydrates and proteins, thereby decreasing their hydrolysis. Phytate has detrimental effects 
on the environment through eutrophication [2]. Phytate with a negative charge acts as an antinutritional factor through chelating minerals with positive charges, such as iron, calcium and zinc. This results in the bioavailabilities of these minerals being decreased in the bodies of monogastric animals and poultry [3,4]. The fact that the principal source of food of monogastric animals is phytate-rich plants, the degrading of phytate by an appropriate phytase enzyme should be taken into consideration to liberate phosphorous and to avoid the antinutritional effects of phytate [5,6]. Sources of phytases are animals, plants and microorganisms, including yeasts, other fungi and bacteria. Phytases have different structures and catalytic mechanisms according to their sources and can be grouped as $\beta$-propeller phytases, purple acid phytases, cysteine phytases and histidine acid phosphatases (HAPs). The most envisaged groups of phytases are histidine acid phosphatases (HAPs), as shown in Figure 1, and $\beta$-propeller phytases, as shown in Figure 2. They have different catalytic mechanisms and similar products $[7,8]$. Furthermore, phytases are classified based on the first phosphate that is liberated from the inositol ring of phytic acid, including 3-phytases (EC: 3.1.3.8), 6-phytases (EC: 3.1.3.26) and 5-phytases (EC: 3.1.3.72), as shown in Figure 3. Microbial phytases from Aspergillus, Escherichia and Bacillus species are widely studied for industrial applications $[9,10]$. There are some challenges to the use of the phytase enzyme in monogastric animals, including high temperature during the pelleting process from 65 to $95^{\circ} \mathrm{C}$ and acidic $\mathrm{pH}$ range (2.5-5.5). Despite the resistance of the desired phytase enzyme to high temperature, its optimum activity should be in accordance with the body temperature of poultry $\left(41^{\circ} \mathrm{C}\right.$ to $\left.42^{\circ} \mathrm{C}\right)$ [11], as shown in Figure 4 . Resistance to proteolytic degradation in the digestive tract and the high activity of phytase are additional advantages [12]. Therefore, the desired phytase should have stability against high temperature, acidic $\mathrm{pH}$ and proteases (pepsin and trypsin) [13,14]. So, to use phytase as an industrial enzyme, stability should be increased. Detecting and rigidifying flexible regions through the use of computational analysis is a powerful approach in the stabilization of enzymes. Two prevalent approaches, including root mean square deviation (RMSD) and root mean square fluctuation (RMSF) are usually used to detect overall flexibility and flexible sites in the phytase structure. B-factor is used as an indicator to find thermolabile residues [15]. In this review, all four required properties (thermostability, acid stability, protelolysis stability and improved activity) for the industrial application of phytase are considered, based on the results of several studies done in recent years.

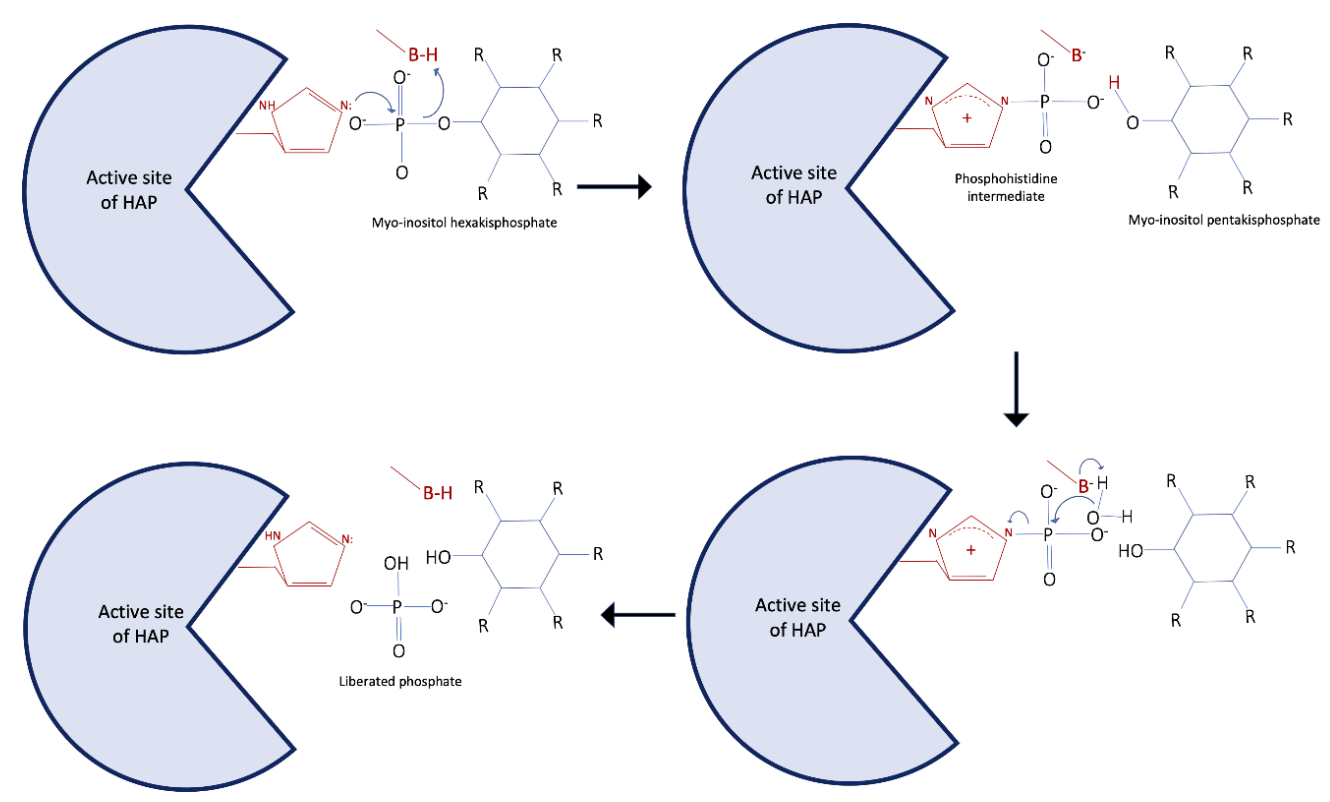

Figure 1. Catalytic mechanism of histidine acid phosphatases. Histidine residue of the conserved RHGXRXP motif acts as a nucleophile and forms phosphohistidine intermediate. The intermediate is hydrolyzed after the water molecule attacks the phospho group of the phosphohistidine to generate a free phosphate. 


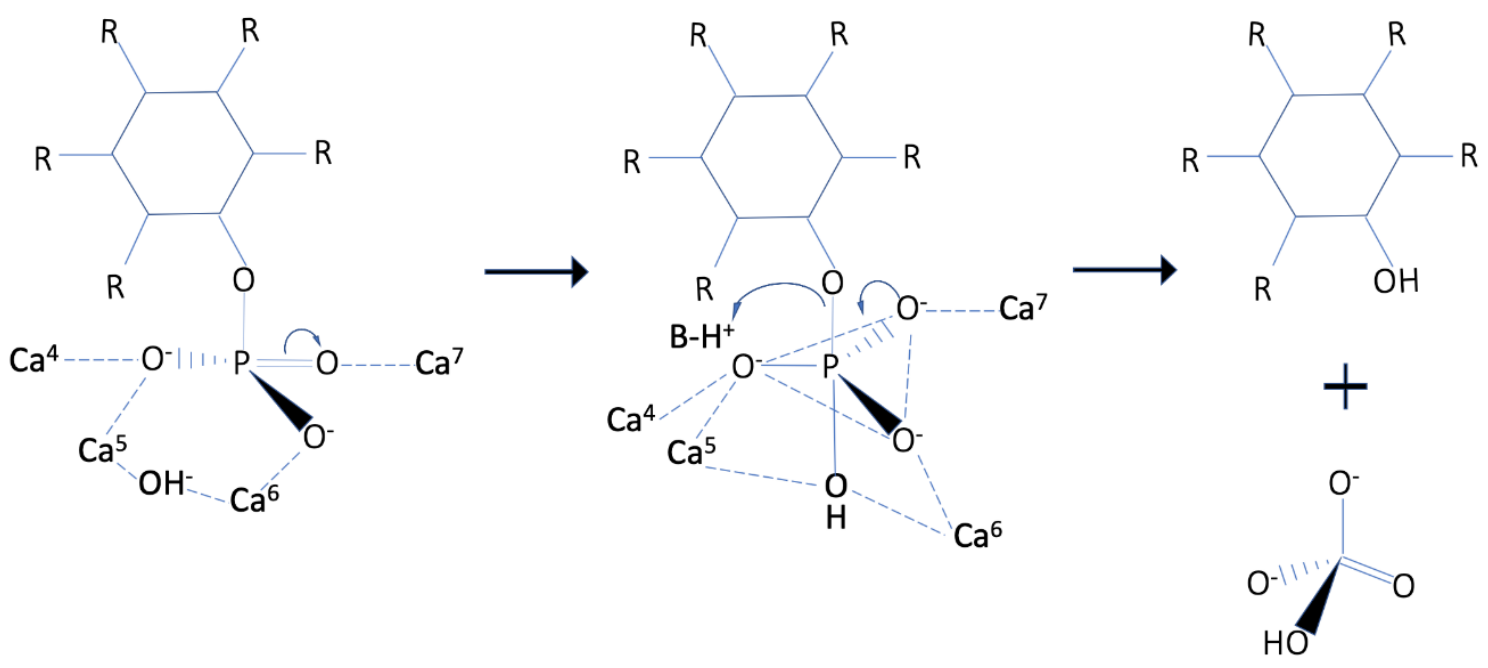

Figure 2. Catalytic mechanism of BPP. The Ca2+ ions decrease $\mathrm{pKa}$ of water forming hydroxide ion (deprotonated form of water). $\mathrm{OH}$ - donates an electron pair to the positive phosphorus in phosphate to form intermediate state. Then, the general acid donates a proton, thus cleaving the phosphoester bond to release phosphate group.

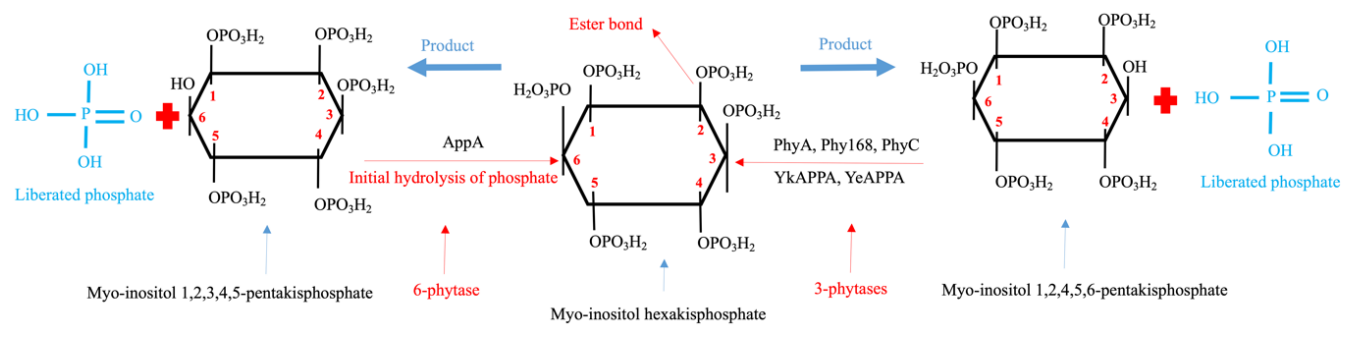

Figure 3. Catalytic reactions of 3 and 6-phytases3-phytases start the hydrolysis of ester bond between phosphate group and inositol ring at position C3, while 6-phytases start to attack at position C6 of inositol ring and liberate phosphate.

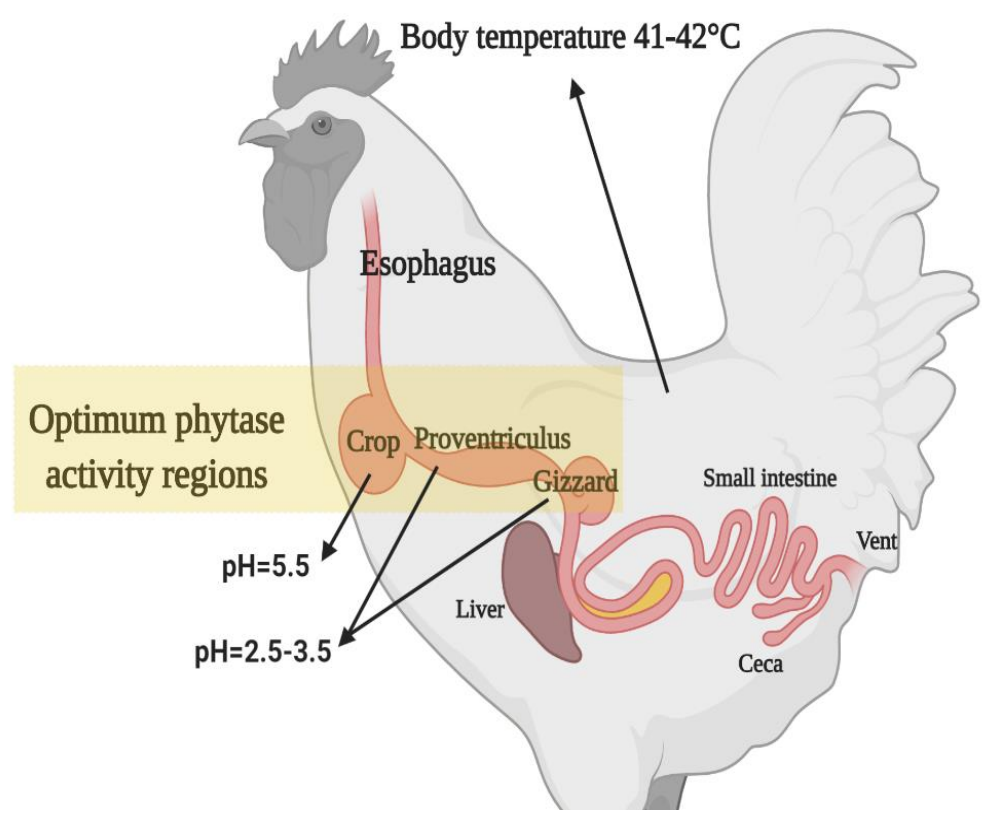

Figure 4. Phytase activity regions with their $\mathrm{pH}$ ranges are highlighted with yellow color. Body temperature of chicken for optimum phytase activity is shown at upper part of figure. 


\section{Modifications of Phytases}

Many studies have been conducted over the last two decades until now to improve the properties of microbial phytases as feed additive to gain resistance to high temperature, acidic condition and proteolytic degradation in the pelleting process and in the digestive tracts of monogastric animals. Improvements in phytase activity were considered in some studies. The directed evolution and the site-directed mutagenesis approaches had been used to construct random libraries of mutants, and the desired library of mutants, based on bioinformatic information, was utilized for predictions of phytase structures [16].

\subsection{Improved Thermostability in Phytase}

During the pelleting process to prepare food for monogastric animals, phytase should tolerate high temperatures from $65^{\circ} \mathrm{C}$ to $95^{\circ} \mathrm{C}$ [17]. Phytase enzymes from Aspergillus niger, Escherichia coli, Yersinia species and Bacillus species had been mainly studied to enhance their thermostabilities for industrial applications, as shown in Table 1. Several improved thermostable phytases are discussed, based on the decisive modifications in their structures.

\subsubsection{Aspergillus Phytases}

Heat tolerance is one of the prerequisites for the industrial application of phytase enzymes. Recently, many studies have been carried out on different microbial phytases with higher potency in order to produce phytase with the desired properties. Noorbatcha et al. carried out a molecular dynamic study to reveal thermostability factors in PhyA phytase from Aspergillus niger. RMSD values were calculated for backbone, side chain atoms and other secondary structure elements at 333 and $353 \mathrm{~K}$ to assess the effects of a quadruple mutation (A35E/P42S/Q168R/T248R) on Aspergillus niger phytase (ANP). It was revealed that mANP (Mutant Aspergillus niger phytase) had lower RMSD values for all atoms over that of the ANP at $333 \mathrm{~K}$. Turn and coil showed the most significant discrepancies in average RMSD with 0.39 and $0.32 \AA$ at $333 \mathrm{~K}$, respectively. Calculating the radius of gyration for ANP and $\mathrm{mANP}$ at $333 \mathrm{~K}$ illustrated that $\mathrm{mANP}$ had a more compact structure than that of ANP, which arose from a higher number of H-bonds. Both mANP and ANP showed similar compactness at $353 \mathrm{~K}$, which resulted from an increase in the number of salt bridges in both of them. The stabilization of the loop regions by introducing a quadruple mutation caused the increased thermostability of mANP at $353 \mathrm{~K}$, as mutations T248R, P42S and Q168R were located in the loops. The Q168R mutation was considered a contributing factor in the thermostability of mANP, because most structural variations in mANP at $353 \mathrm{~K}$ were localized at the Arg163-Gln168 area. As a result of introducing residues Glu35 and Arg248, new hydrogen bonds were formed that further enhanced the thermostability of mANP. Glu35 and Arg248 mutants also introduced two new salt bridges that were thought to increase thermostability in mANP. Although ANP showed an increased number of salt bridges compared to $\mathrm{mANP}$ at $353 \mathrm{~K}$, mANP showed higher thermostability. Thus, the location of the salt bridge was more important than the number of salt bridges for thermostability [18]. 
Table 1. Enhancement of the thermostabilities of various microbial phytases via protein engineering.

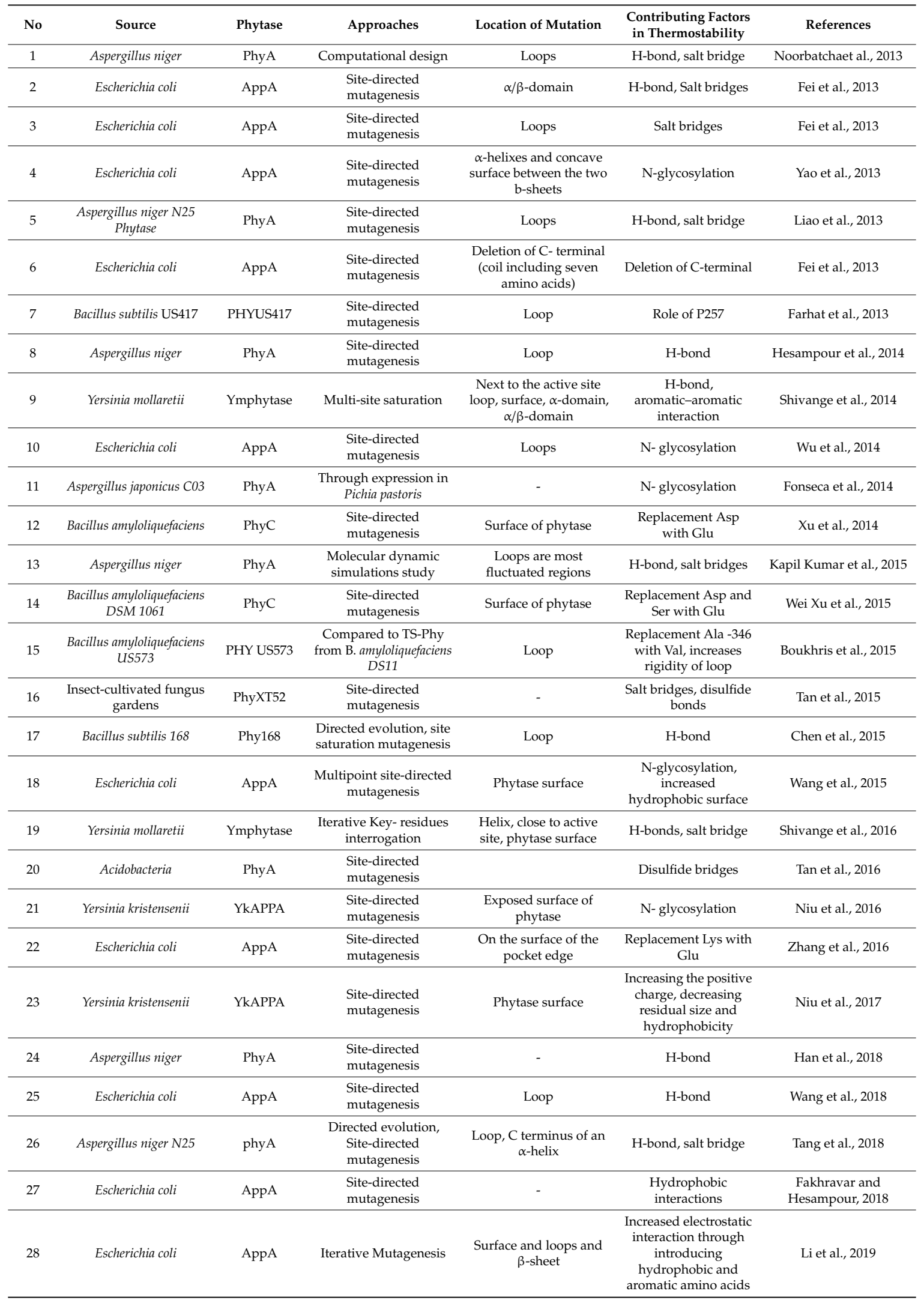


The double mutant I44E/T252R-PhyA, which was designed based on the Aspergillus niger N25 phy $\mathrm{A}^{\mathrm{m}}$ gene, showed $35 \%$ enhancement in thermostability compared to the native phytase at $80^{\circ} \mathrm{C}$ for $10 \mathrm{~min}$. Structural analysis revealed that I44E was situated on the loop area of the $\alpha / \beta$ domain. Two hydrogen bonds were introduced between E44 and S45, and one hydrogen bond was also formed between E44 and L422. The tertiary structure of phytase could be reinforced as a result of introducing hydrogen bonds between E44 and S45. The hydrogen bond network at the loop area S42-D47 was constituted through hydrogen bonds between E44 and S45, resulting in the reinforcement of the tertiary structure in PhyA. Additionally, a new salt bridge was introduced between E44 and R404 that was situated on the $\beta$-sheet of the $\alpha / \beta$ domain structure. Mutation T252R on the loop area in the $\alpha$-domain, introduced two additional hydrogen bonds to D248, which was situated on the adjacent of the $\alpha$-helix. A side chain-side chain hydrogen bond was also formed between T252R and T254. Based on the location of both the I44E and T252R mutations that were on the loops, it was concluded that loops had a high potential to accept mutations compared to other areas in the phytase structure. The stabilization of the loop region and the adjacent $\alpha$-helix was a result of two side chain-side chain hydrogen bonds and one salt bridge between T252R with D248 and T254 [19].

Mutants P9 (T314S Q315R V62N) and P12 (S205N S206A T151A T314S Q315R) from Aspergillus niger PhyA displayed 24 and $22.6 \%$ improvements in residual activities over that of the native phytase at $80{ }^{\circ} \mathrm{C}$, respectively. The P9 and P12 variants showed 35 and $20 \%$ decrements in $\mathrm{K}_{\mathrm{m}}$ values compared to PhyA, respectively. The P9 and P12 mutants showed 5 and $4.6^{\circ} \mathrm{C}$ improvements in $\mathrm{T}_{\mathrm{m}}$ over that of the wild-type, respectively. These findings indicate that the number of main-chain H-bonds in P9 and P12 was improved by two and five interactions compared to the wild-type, respectively. These results revealed that residue T314 introduced two H-bonds with G318 and P310, while substitution T314S in both mutants introduced three H-bonds with G460, G312 and H311. The location of substitution T151A in the P12 mutant was located on a loop area in the $\alpha / \beta$ domain, which was related to thermal stability. In native phytase, T151 formed one H-bond with E148, while in mutant P12, substituted residue A151 formed one H-bond with Y147. Consequently, P9 and P12 showed improvements in thermostability and catalytic efficiency, simultaneously [20].

A high level of glycosylated Aspergillus japonicus C03 phytase was expressed in P. pastoris GS115 with 75 KDa molecular mass. The amino acid sequence analysis of Aspergillus japonicus C03 phytase revealed eight $\mathrm{N}$-glycosylation and three O-glycosylation sites. N6, N38, N84, N99, N209, N218, N355 and N367 showed single GlcNAc. The optimum temperature for the expressed phytase in P. pastoris GS115 was at $50{ }^{\circ} \mathrm{C}$. The half-lives of PhyA were 40, 23 and $7 \mathrm{~min}$ at 50,60 and $70{ }^{\circ} \mathrm{C}$, respectively. The enzyme activity had an $8 \%$ improvement for the first few minutes when it was exposed to high temperature, but it was found that native phytase from Aspergillus japonicas had similar activity with recombinant PhyA. The improved activity could be attributed to conformational changes of the structure when Phy A was exposed to high temperatures. The interaction between the active site and the substrate was enhanced as a result of the fluctuation of residues around the active site [21].

When the PhyA from Aspergillus niger was exposed to high temperature, denaturation started from loops 8 and 14 and broadened to loop 24, located at the C-terminal of the enzyme. Loop 8 , with high flexibility, was the reason for the severe movement of the $\mathrm{H} 2, \mathrm{H} 10$ and $\mathrm{H} 12$ helices at high temperature and denaturation happened based on these instabilities. Partial denaturation occurred when the extreme movement of loop 14 caused the mobilities of the neighboring H7, H8 and H9 helices at $500 \mathrm{~K}$. It was shown that, by increasing the temperature, the lengths of the salt bridges (including Glu125-Arg163, Asp299-Arg136, Asp266-Arg219, Asp339-Lys278, Asp335-Arg136 and Asp424-Arg428) were increased significantly. So as to recognize thermosensitive areas in PhyA, conformational dynamics analysis using RMSD and RMSF values of backbone C $\alpha$ atoms from backbone was employed. MD simulation analysis at $500 \mathrm{~K}$ revealed that backbone atom fluctuation occurred as a result of the decrease in the number of main-chain to main-chain $\mathrm{H}$-bonds. $\beta$-strands indicated lower average RMSF values than loops and helices, which was the pivotal factor in the heat tolerance of PhyA. By increasing the temperature, most thermally sensitive regions, including loops 8 , 
$10,14,17$ and 24, showed intense increments in RMSF values. It was concluded that the location of the salt bridge was more important compared to the number of salt bridges for thermostability [22].

One of the practical approaches to designing thermostable phytase could be an integrative structural comparison of homologous phytases and computational simulation in order to find critical interactions. AnP-M2 (mutant Aspergillus niger PhyA phytase) with nine point mutations showed 37 and $30 \%$ enhancements in thermostability compared to AnP at 80 and $90^{\circ} \mathrm{C}$ for $1 \mathrm{~h}$, respectively. Though the thermostability of AnP-M2 was enhanced, the catalytic efficiency was diminished slightly. AnP-M1 showed a $20 \%$ enhancement in thermostability over that of the AnP at 70 and $80^{\circ} \mathrm{C}$ for $1 \mathrm{~h}$. Nine substitutions were introduced to AnP, based on equivalent sites in AfP (Aspergillus fumigatus phytase), including V39S, P42S, Q165T, P166N, G167R, T248R, V251D, D252A and K254Q, to design AnP-M2. Segment-3, including mutations T248R, V251D, D252A and K254Q, was situated at a small $\alpha$ domain neighboring the catalytic and substrate-binding motifs with around $8 \AA$ distance. The simulation results illustrated that in segment-1, two new H-bonds, including S39-E37 and S42-D405, were probably involved in the improved thermostability. In segment-2, increased thermostability was attributed to the H-bond interactions between R129 and T165 and N166 and R167. In segment-3, increased thermostability was attributed to H-bonds within R248, D251, A252 and Q254. The thermostability observed in this study was acquired through H-bond interactions as a critical factor [23].

Tang and his team employed directed evolution and site-directed mutagenesis approaches on the Aspergillus niger N25 phytase gene and, among all of the mutants obtained, the double mutant Q172R/K432R showed 40\% improvement in thermostability over that of the PP-NPeP-6A (the mutant that had been obtained through error-prone PCR in their previous study) at $80{ }^{\circ} \mathrm{C}$ for $10 \mathrm{~min}$ [24]. The half-life of Q172R/K432R showed a 6.8 min enhancement over that of PP-NPeP-6A. Mutation Q172R was situated on the surface loop, due to the introduction of a salt bridge with D165, which connected a $\beta$-sheet and an $\alpha$-helix, as shown in Figure 5A,B. The loop area was stabilized as a result of introducing this salt bridge. K432R was situated on the surface area at the C-terminus of an $\alpha$-helix, which introduced a strong H-bond and a salt bridge with D428, as shown in Figure 5A,C. Substituting K432 with $\mathrm{R}$ brought about the interaction between the more positively charged $\mathrm{R}$ with the negatively charged C-terminus of the $\alpha$-helix, resulting in the improved thermostability of the phytase. Although Q172R/K432R showed the highest thermostability, its catalytic efficiency was lower over those of the other mutants. This decrement in catalytic efficiency was a trade-off of elevated rigidity [25].
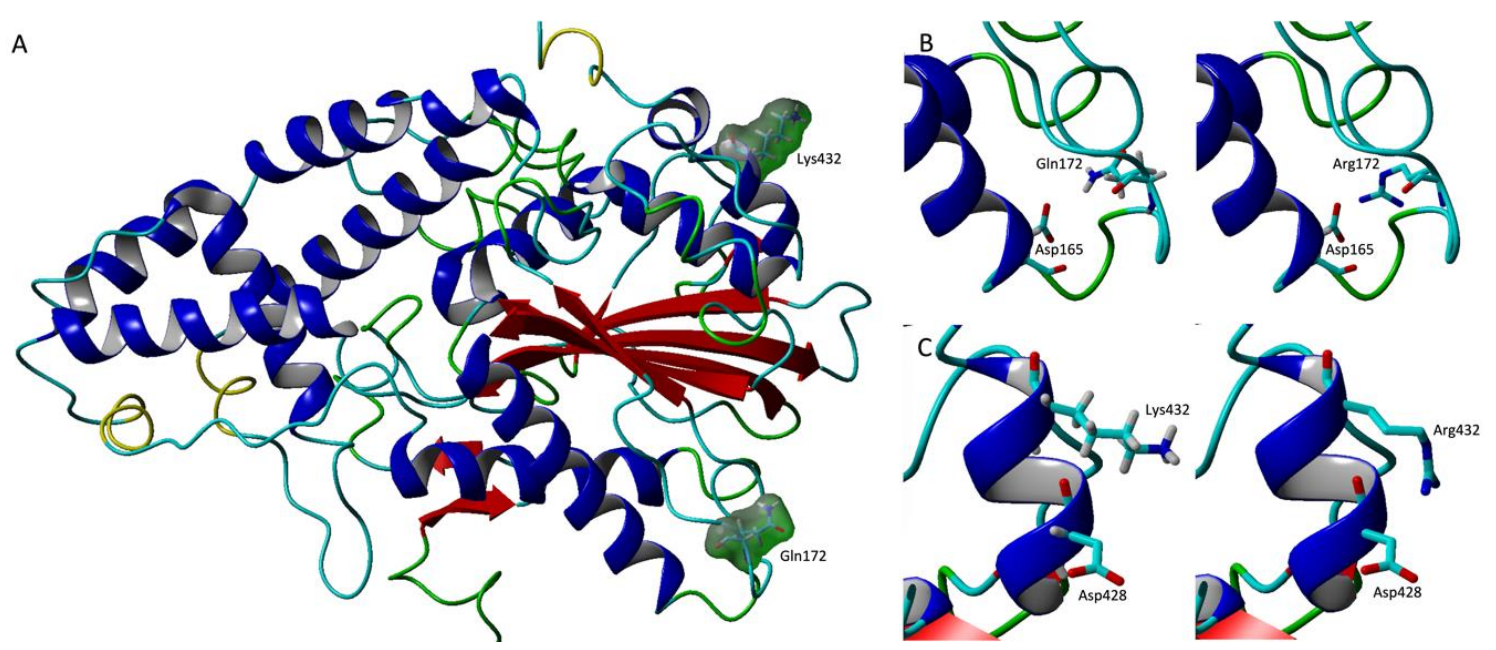

Figure 5. Site-directed mutagenesis on Aspergillus niger N25 phytase. (A) Mutation sites of Q172 and K432. (B) Substitution of Q172R formed a salt bridge between R172 and D165. (C) Substitution of K432R introduced a salt bridge and a new hydrogen bond with D428. 


\subsubsection{Escherichia coli Phytase}

In another study, double mutants were constructed based on structural properties, including salt bridges, protein flexibility and protein surface to improve Escherichia coli AppA phytase. Y311K/I427L showed the highest thermostability by a 30\% improvement in residual activity compared to native phytase after heat treatment at $80^{\circ} \mathrm{C}$ for $10 \mathrm{~min}$. The RMSF values were examined in order to determine thermal unstable regions. These thermo-labile residues are usually placed in surface loops or turn. To form salt bridges, uncharged residues in thermo-labile areas were chosen to introduce mutations for constructing them. Substitution Y311K formed a salt bridge with Asp144. Y311K and I427L substitutions in the $\alpha / \beta$-domain of the AppA adjacent to the C-terminus could synergistically stabilize the local structure. Since AppA unfolding was started from the C-terminal at high temperature, the synergistic effect of the double mutation $Y 311 \mathrm{~K} / \mathrm{I} 427 \mathrm{~L}$ brought about an additional increase in catalytic efficiency. Y311K and I427L in the $\alpha / \beta$-domain were involved in substrate binding [26].

In a study by Fei et al., the importance of salt bridge interactions in the thermostability of Escherichia coli AppA was assessed. A salt bridge with subtracted E31Q and a salt bridge with added Q307D were made, based on Escherichia coli AppA, to assess the impact of the salt bridge on thermostability. After treating at $80^{\circ} \mathrm{C}$ for $10 \mathrm{~min}, \mathrm{Q} 307 \mathrm{D}, \mathrm{E} 31 \mathrm{Q}$ and native AppA phytase retained $40.57 \%, 17.46 \%$ and $31.42 \%$ of their initial activities, respectively. Q307D improved thermostability by $13.96 \%$ compared to native AppA. It was concluded that the salt bridge was a vital factor in thermostability. The Arg359-Glu31-Arg361 salt bridge network was formed as a result of the constitution of a salt bridge between E31 with R359 and R361, respectively. Substitution Q307D constituted an additional salt bridge with residue $\mathrm{H} 304$ with a distance of $4.1 \AA$. Q307 was situated at the turn, while E31 was situated at the $\beta$-sheet. RMSF calculations proved that the contributing residues in the salt bridge interaction had lower than $2 \AA$ values. The lowest RMSF value was attributed to the salt bridge network Arg359-Glu31-Arg361. So, salt bridges led to increased stability in amino acid residues. These results showed that introducing salt bridge interaction could improve the stability of residues by increasing rigidity at the targeted regions. Based on the position of the thermostable mutants, it was suggested that the $\alpha / \beta$ domain was an important structural part in thermostability. Additionally, E31 was important in AppA's thermostability [27].

Baojin Fei et al. conducted an experiment on the role of the C-terminus of Escherichia coli AppA phytase on heat tolerance. C-lose mutant (removed C-terminal) indicated 39.07\% improvement in thermostability compared to AppA at $80^{\circ} \mathrm{C}$ for $10 \mathrm{~min}$. A computational analysis of the $\mathrm{C}$-terminal revealed that it was the flexible coil situated at the $\alpha / \beta$-domain which rendered instability to Escherichia coli AppA phytase. Additionally, P428, A429 and C430 residues formed a 3-10-helix in the $\mathrm{C}$-terminus. The $\mathrm{C}$-terminal region formed three internal hydrogen bonds as a result of the interactions between I427 and C430 and P428 and S431. The C-terminal contained four external hydrogen bonds as a result of the interactions between R426 and V422, R426 and D295 and I427 and T291. Additionally, one disulfide bond was observed at the C-terminal between C430 and C155. This showed that, when AppA phytase was exposed to a high temperature, the denaturation of the enzyme started from the C-terminal region. Thus, the deleted C-terminal mutant should be taken into consideration from a thermostability perspective [28].

Another study used the glycosylation approach to increase thermostability in Escherichia coli AppA. Q258N and Q349N mutations were constructed according to the structural and analogical features of glutamine and asparagine at the Q-X-S/T motif to improve glycosylation in AppA. AppAQ258N/Q349N indicated $40 \%$ improvement in thermostability at $85^{\circ} \mathrm{C}$ for 10 min over that of AppA-WT, and $4-5{ }^{\circ} \mathrm{C}$ improvement in melting temperature compared to wild-type AppA. As a result of improved glycosylation in the AppA-Q258N and AppA-Q258N/Q349N mutants, they showed different molecular masses compared to AppA-WT before and after deglycosylation. Crystal structure analysis revealed that Q258N was situated at the end of the $\alpha$-helix, but Q349N was located at the surface between two $\beta$-sheets. Hydrogen bonds between the side-chain of N349 and the carboxylate group of Q336, and the side-chain of N309 and the carboxylate group of Q258, increased the feasibility that glycosylation 
favored the reorientation of the peptide chain. Mutations Q258N and Q349N showed distinct levels of glycosylation enhancement [29]. Based on CbAppA (Citrobacter phytases), the glycosylation of EcAppA (Escherichia coli phytase) was changed in order to increase thermostability. Four mutants were designed in EcAppA, based on the N-glycosylation motifs of CbAppA. Different loops of EcAppA adopted these motifs. Three N-glycosylation motifs, Mut1 (74-NQT-76), Mut2 (171-NFS-173) and Mut4 (282-NGT-284) showed 5.2, 2.6 and 3.1\% enhancements in thermostabilities after being heated at $80^{\circ} \mathrm{C}$ compared to native EcAppA, respectively. The triple Mut $1 / 2 / 4$ mutant with $33.1 \%$ residual activity at $66^{\circ} \mathrm{C}$ was the most thermostable variant. Introducing the glycosylation pattern of CbAppA enhanced the thermostability of EcAppA phytase [30].

A team analyzed the contributing factors in enhancing the melting temperature in AppA phytase from Escherichia coli. The AppA-M10 mutant was constructed through introducing ten substitutions (including W46E, Q62W, A73P, K75C, S146E, R159Y, N204C, Y255D, Q258N and Q349N). The $\mathrm{T}_{\mathrm{m}}$ of AppA-M10 was increased by $7.5{ }^{\circ} \mathrm{C}$ over that of the native phytase. Based on comparative conformational analysis, AppA-M10 was improved from the $\alpha$-helix content perspective and it also displayed higher exposed hydrophobic surface, compared to the native phytase, resulting in its improved thermostability. Structural analysis revealed that the positions of the mutations were situated on or close to the surface of phytase. Hence, glycans on substitutions Q349N and Q258N with two potential glycosylation positions were involved in the conformational stabilization of the AppA-M10 mutant at high temperature [31].

Based on site-directed mutagenesis on the AppA phytase gene from Escherichia coli, mutant $\mathrm{K} 24 \mathrm{E}$ was constructed that retained more than $60 \%$ of its initial activity at 70,80 or $90^{\circ} \mathrm{C}$ for 20 min, these being temperatures in which native phytase did not show any activity. The K24E mutant was situated on the surface of the pocket edge and adjacent to the active center site. Three dimensional conformations of K24E and AppA showed they had the same structure [32]. Wang and his colleagues constructed a mutant with six mutation sites according to the three-dimensional structure and $\mathrm{H}$-bond analyses, and AppA-M6 showed a $3.8^{\circ} \mathrm{C}$ enhancement in melting temperature over that of the WT. Six substitutions, K74D/K75Q/K180N/R181N/K183S/K363N, located on the surface loops, reinforced hydrogen bonding. A strong new H-bond was introduced between D74 and Q75. Two H-bonds were introduced between N180 and N176, which were situated on the loop and the adjacent $\alpha$-helix areas, respectively. It was likely that these two H-bonds stabilized the interaction between the $\alpha$-helix and the loop, resulting in increased phytase stability. Increased H-bonding was observed between N363 and E53. Increased thermostability was obtained as a result of introducing hydrogen bond and $\mathrm{N}$-glycosylation through the increased rigidity of phytase [33].

Based on rational design on AppA, phytase S392F was constructed. The thermostability of mutant S392F was increased by 74 and $78.4 \%$ at $80^{\circ} \mathrm{C}$ and $90^{\circ} \mathrm{C}$ over that of the native phytase, respectively. Structural comparisons between the mutant and native phytase revealed that substituting Ser392 with Phe caused two new hydrophobic interactions with Trp 347, which brought about the elevated structural stability of Escherichia coli AppA phytase, as shown in Figure 6. Along with the increase in thermostability, the catalytic efficiency of the mutant was also increased by $25.6 \%$ through introducing hydrophobic interactions [34]. Based on the highest B-values, nine substitutions (P41W, V42S, K43L, R181S, E182S, Q285D, K286Y, E384V, R385A) were made and four more substitutions (S80I, Q184A, $\mathrm{S} 342 \mathrm{~T}, \mathrm{E} 383 \mathrm{~A}$ ) on the surface loop were carried out for protein surface engineering. Mutant P56214 showed $55 \%$ improvement in thermostability over that of the native phytase at $90^{\circ} \mathrm{C}$ for $5 \mathrm{~min}$, while as a trade-off the catalytic efficiency was decreased significantly. The modification in protein surface residues improved electrostatic interactions and decreased protein flexibility (entropy). All the thirteen selected amino acid residues, such as Glu, Arg, and Lys, were charged and polar. Charged amino acids are normally low in thermophilic proteins. Mutated residues were mainly aromatic and hydrophobic amino acids. Substituting hydrophobic and low B-value amino acids in the protein surface and highly flexible areas gave two benefits to thermostability: firstly, aromatic and hydrophobic amino acids could 
elevate the hydrogen bonding network and enhanced electrostatic interactions; secondly, they could reduce the flexibility of the protein structure [35].
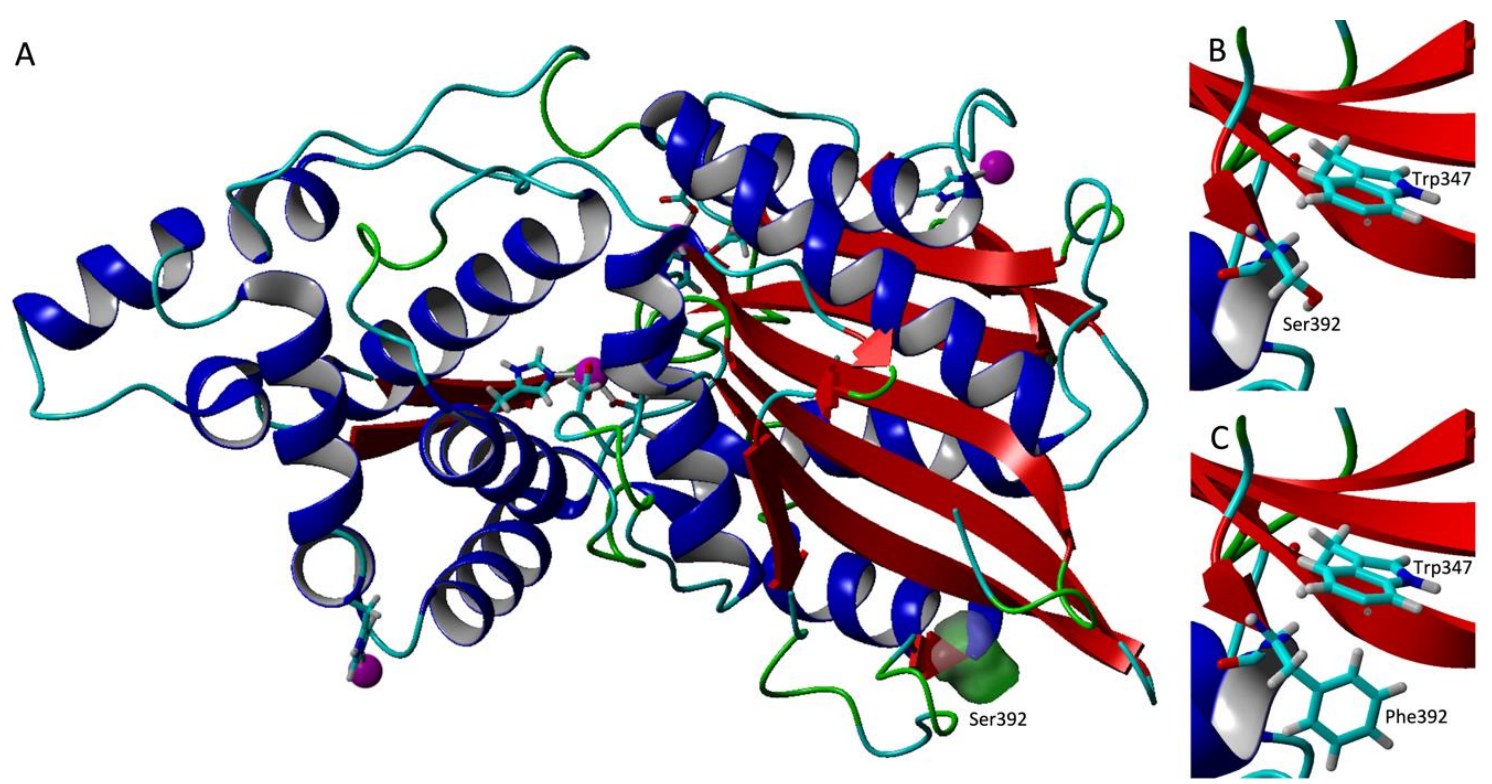

Figure 6. (A): Mutation site of S392. (B): Location of residues S392 and W347. (C): Substitution of S392F, which introduced two hydrophobic interactions with W347.

\subsubsection{Bacillus Phytases}

The role of residue P257 in the thermostability of phytase PHY-US417 derived from Bacillus subtilis was examined by employing two mutations-P257R and P257A. P257R and P257A showed 64.4 and $81.5 \%$ residual activities after being heated at $75{ }^{\circ} \mathrm{C}$ for $30 \mathrm{~min}$. P257R showed significant decrements in thermostability, catalytic efficiency and specific activity. Structural analysis indicated that P257 was located on a surface loop connecting two of the six characteristic $\beta$-sheets. P257 brought about higher thermostability through diminishing the local thermal flexibility of the loop. PHY US417 with residue P257 was an enhanced thermostable phytase over that of the PhyC with R257 (both of the Bacillus subtilis phytases), the only substitution between these two phytases [36]. Substitution D191E was introduced to phyC from Bacillus amyloliquefaciens in order to increase thermostability. The D191E mutant showed a $4.5^{\circ} \mathrm{C}$ increment in half inactivation temperature compared to phyC. $\mathrm{D} 191 \mathrm{E}$ retained $40 \%$ of its initial activity after being heated at $85^{\circ} \mathrm{C}$ for $10 \mathrm{~min}$. Although the D191E substitution brought about higher thermostability as a result of a decrement in flexibility, the rigidity of the phytase caused a significant decrement in activity of around $45 \%$ phyC. Structural analysis showed that, although the semi-conserved residue D191 was far from the active site, it was a decisive factor for phytase activity. Thus, there was an inverse relationship between thermostability and activity trade-off. Substitutions of semi-conserved residues that played important roles in maintaining enzyme activity increased thermostability [37]. After being heated at $70^{\circ} \mathrm{C}$ for $10 \mathrm{~min}, \mathrm{D} 148 \mathrm{E}$ and S197E indicated around $9.5 \%$ and $5 \%$ enhancements in thermostability over that of the native phytase, respectively. Therefore, substituting Asp and Ser (semi-conserved residues) with Glu led to increased activity and thermostability [38].

Phytase from Bacillus amyloliquefaciens US573 (isolated from geothermal soil) retained 93, 62.8 and $50 \%$ of its initial activity at 75,90 and $100{ }^{\circ} \mathrm{C}$, respectively, for $10 \mathrm{~min}$. Its thermostability depended on calcium ion. The TS-Phy of B. amyloliquefaciens DS11 and the phytase from Bacillus sp. MD2 with the highest thermostability among the bacterial phytases, indicated 50 and $40 \%$ residual activity in the presence of a similar concentration of $\mathrm{CaCl}_{2}$ when being heated at 90 and $100^{\circ} \mathrm{C}$ for 10 min, respectively. Structural analysis of PHY US573 was conducted, based on TS-Phy phytase. Most likely three of the five dissimilar residues, including D148, L377 and V346, brought about enhanced thermostability 
compared to TS-Phy phytase. The substituted A346V was located on the loop adjacent to the calcium ion binding sites, $\mathrm{Ca} 1$ and $\mathrm{Ca} 2$, which played important roles in thermostability. The mobility of the loop was decreased as a result of substitution A346V, which enhanced the thermostability of PHY US573 compared to that of TS-Phy phytase [39].

Chen and colleagues conducted directed evolution studies on phytase from Bacillus subtilis 168. Docking analysis of mutant D24G indicated that the H-bond between A26 and K49 could be introduced through turning the carboxyl group of A26 by substitution D24G. Therefore, the improved thermostabilities of mutants D24G, D24G/K265N and D24G/K70R/K111E/N121S occurred as a result of the additional H-bond between A26 and K49. Mutants D24G, D24G/K265N and D24G/K70R/K111E/N121S showed 30.9, 25.3 and 27.8\% improvements in residual activities compared to native phytase at $70{ }^{\circ} \mathrm{C}$, respectively [40].

\subsubsection{Yersinia Phytases}

In order to increase the thermostability of Yersinia mollaretii phytase, Omni 1 was constructed. Mutant Omni 1 with substitutions D52E, K139T, G187S, and V298F showed a 32\% enhancement in residual activity at $58^{\circ} \mathrm{C}$ for $20 \mathrm{~min}$ over that of the native Yersinia mollaretii phytase. Besides, Omni 1 showed a $2{ }^{\circ} \mathrm{C}$ enhancement in melting temperature over that of the native phytase. Substitution V298F improved phytase stability through introducing aromatic-aromatic interactions with F420. H-bonds with the neighboring loop were introduced through mutation G187S. A H-bond was formed between the side-chain of the D52E substitution with the backbone atom of Y197. A side chain-side chain H-bond was formed between substitutions K139T and D137. Substitutions D52, K139T, G187S and V298F were located on the neighboring active site loop, phytase surface, $\alpha$-domain and $\alpha / \beta$ domain, respectively. Aromatic-aromatic interactions and hydrogen bonding contributed to improved thermostability [41].

Shivange et al. demonstrated the structural properties of the enhanced thermostability mutant from Yersinia mollaretii phytase. Multiple mutant M6, including substitutions T77K, Q154H, G187S and $\mathrm{K} 289 \mathrm{Q}$, showed a $54 \%$ enhancement in residual activity over that of the native phytase after incubation at $58{ }^{\circ} \mathrm{C}$ for $20 \mathrm{~min}$. Besides, $\mathrm{M} 6$ indicated a $3{ }^{\circ} \mathrm{C}$ improvement in melting temperature. Based on molecular dynamics simulation analyses, the stabilization of loops adjacent to the $\mathrm{B}, \mathrm{F}$ and K helices with mutations T77K, G187S, and K289Q, respectively, were observed. Reinforced H-bond networks, such as G187S and K289E/K289Q, and introducing salt bridge through the substitution of $\mathrm{T} 77 \mathrm{~K}$, increased stability in the loops. RMSF values over the last $10 \mathrm{~ns}$ simulation time indicated that loops B4 and K10 in the M6 variant were more stable than those of the native enzyme. The substitution of T77K situated at helix B introduced a salt bridge to D122 that was situated at helix C and, as a result of this interaction, the two helixes were stabilized. Simulation analysis showed that loop K10 was the most flexible region in the native phytase. The hydrogen bonding network between helix $\mathrm{L}$ and $\mathrm{K}$ was enhanced through the substitution of K289Q. Consequently, the stabilization of loop K10, that was adjacent to helix K, increased significantly. The thermostability of phytase could be improved by the enhanced H-bond network of the $\alpha$-helix, which was located close to the flexible loops. G187S introduced four H-bonds to loop-G6, two to three H-bonds were formed between K289Q and helix-L and 1-2 H-bonds were also introduced between K289Q and loop-CD. Solvent exposure might be enhanced as a result of a charged residue due to mutant Q154H [42].

Doubly N-glycosylated variant YkAPPA-D397N/K399T showed a $12.1 \%$ enhancement in thermostability over that of the native YkAPPA at $60^{\circ} \mathrm{C}$ for $2 \mathrm{~h}$. while a deglycosylated mutant showed reduced thermostability at $60^{\circ} \mathrm{C}$. Interactions between $\mathrm{N}$-linked glycan and phytase could enhance structural stability. This experiment was initially aimed to improve the tolerance of the phytase against acidic $\mathrm{pH}$ and pepsin degradation through introducing $\mathrm{N}$-glycosylation. Concomitantly, the thermostability of the phytase was also increased [43]. YkAPPA-F89S/E226H showed a 44\% improvement in thermostability over that of YkAPPA at $70{ }^{\circ} \mathrm{C}$ for $30 \mathrm{~min}$. Increased thermostability was observed as a result of reducing hydrophobicity and residual size through substitution F89S. 
Elevating the positive charge of E226H increased thermostability through optimizing the surface charge-charge interaction [44].

\subsubsection{Other Phytases}

Tan et al. screened publicly available metagenomes of fungus gardens, which enabled the bioinformatic mining of phytases. Their findings revealed that the positions of the salt bridges played more important roles in heat tolerance than the number of salt bridges. When rPhyXT52 was exposed at $80{ }^{\circ} \mathrm{C}$ for $20 \mathrm{~min}$, residual activity was $90 \%$. Moreover, rPhyXT52 retained $93 \%$ and $83 \%$ of its initial activities after incubation at $100^{\circ} \mathrm{C}$ for 15 and $20 \mathrm{~min}$, respectively. The half-lives for rPhyXT52 were $27 \mathrm{~min}$ and $2.1 \mathrm{~h}$ after incubation at 100 and $80{ }^{\circ} \mathrm{C}$, respectively. Several partially and one completely disabled salt bridge mutants were designed to analyze the effects of seven salts bridges in thermostability. Mutants rPhyXT52: $\triangle \mathrm{SB} 1,5$ and rPhyXT52: $\triangle \mathrm{SB} 2,3$ with two salt bridges lost showed

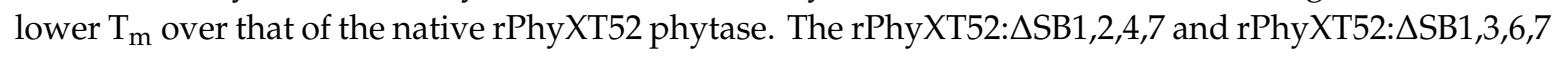
mutants with four disabled salt bridges showed additional decrements in $\mathrm{T}_{\mathrm{m}}$ over those with two disabled salt bridges. The rPhyXT52: $\triangle$ SB1-7 mutant with all (seven) disabled salt bridges indicated the lowest $\mathrm{T}_{\mathrm{m}}$, with a $7.7^{\circ} \mathrm{C}$ decrement over that of the native phytase. It was reported that mutants with more disabled salt bridges were less thermostable, while those with less disabled salt bridges were more thermostable. Consequently, salt bridges played vital roles in the thermostability of rPhyXT52. Structural analysis illustrated that the hydrophobic $\beta$-sheet was surrounded by DS1, DS2 and DS3 disulfide bonds. Hence, it would be practical to lock the $\beta$-sheet inside the phytase to stabilize the packing of the hydrophobic core. The thermostability of rPhyXT52 was most likely attributed to the structural properties of this phytase. Salt bridges and disulfide bonds were formed on the surfaces of phytases [45]. Tan and his team showed the impact of additional disulfide bonds in thermostability. Four disulfide bridges were introduced to Acidobacteria phytase to construct mutant rPhyA6DB. The half-lives of rPhyA6DB were 3.0 and 2.8 times longer than those of native phytase at $60^{\circ} \mathrm{C}$ and $80^{\circ} \mathrm{C}$, respectively. The optimum temperature and the melting temperature of the mutant were increased by $15^{\circ} \mathrm{C}$ and $13^{\circ} \mathrm{C}$ over those of the native phytase. The selection of four potential disulfide bridges was based on the higher B-factor value and distance between the two Cys residues in the peptide strands [46], as shown in Figure 7.

\subsection{Improved Acid Stability}

The $\mathrm{pH}$ range in the digestive tract of chicken is between 2.5-5.5. The $\mathrm{pH}$ in the crop is 5.5, and in the proventriculus and gizzard they are 2.5 to 3.5 . Exogenous phytase activity mainly occurred in the abovementioned three upper parts of the digestive tract. Hence, phytase should be stable at these $\mathrm{pH}$ ranges [47]. Here, details in the latest studies were examined to find contributing factors, as shown in Figure 8, for the acid stability of phytases, as shown in Table 2.

Table 2. Factors affecting phytase acid stability.

\begin{tabular}{|c|c|c|c|c|c|c|}
\hline No. & Source & Phytase & Approaches & Location of Mutation & $\begin{array}{l}\text { Contributing Factor in } \\
\text { Acid Stability }\end{array}$ & References \\
\hline 1 & Aspergillus neoniger & PhyAn & $\begin{array}{l}\text { Site-directed } \\
\text { mutagenesis }\end{array}$ & Catalytic motif & Positively charged residues & Zhou et al., 2019 \\
\hline 2 & Escherichia coli & AppA & $\begin{array}{l}\text { Site-directed } \\
\text { mutagenesis }\end{array}$ & Surface of pocket edge & $\begin{array}{l}\text { Decreased isoelectric point } \\
\text { through substitution K24E }\end{array}$ & Zhang et al., 2016 \\
\hline 3 & Yersinia mollaretii & Ymphytase & $\begin{array}{l}\text { Directed evolution, } \\
\text { multi-site saturation } \\
\text { mutagenesis }\end{array}$ & $\begin{array}{c}\text { Close to active site } \\
\text { loop, surface area, } \\
\alpha \text {-domain, } \\
\alpha / \beta \text {-domain }\end{array}$ & $\begin{array}{l}\text { Epistatic effect of four } \\
\text { substitutions which } \\
\text { introduced H-bonds and } \\
\text { aromatic interactions }\end{array}$ & Shivange et al., 2014 \\
\hline 4 & $\begin{array}{l}\text { Yersinia kristensenii, } \\
\text { Yersinia enterocolitica }\end{array}$ & $\begin{array}{l}\text { YkAPPA, } \\
\text { YeAPPA }\end{array}$ & $\begin{array}{l}\text { Site-directed } \\
\text { mutagenesis }\end{array}$ & Phytase surface & $\mathrm{N}$-glycosylation & Niu et al., 2016 \\
\hline 5 & Yersinia kristensenii & YkAPPA & $\begin{array}{l}\text { Site-directed } \\
\text { mutagenesis }\end{array}$ & Phytase surface & $\begin{array}{l}\text { Decreased hydrophobicity, } \\
\text { increased positive } \\
\text { surface charge }\end{array}$ & Niu et al., 2017 \\
\hline
\end{tabular}




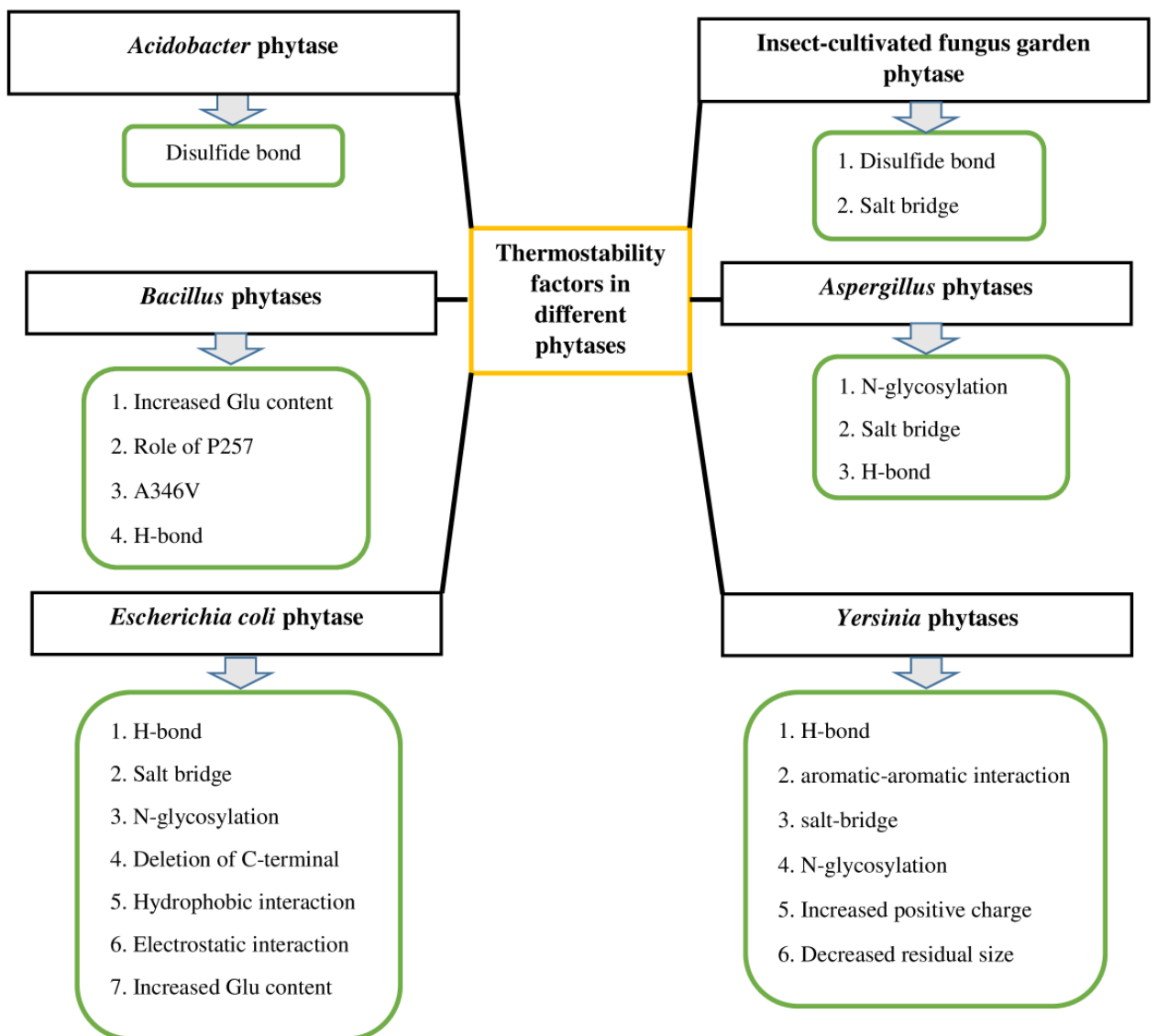

Figure 7. Thermostability factors in phytases from different sources.

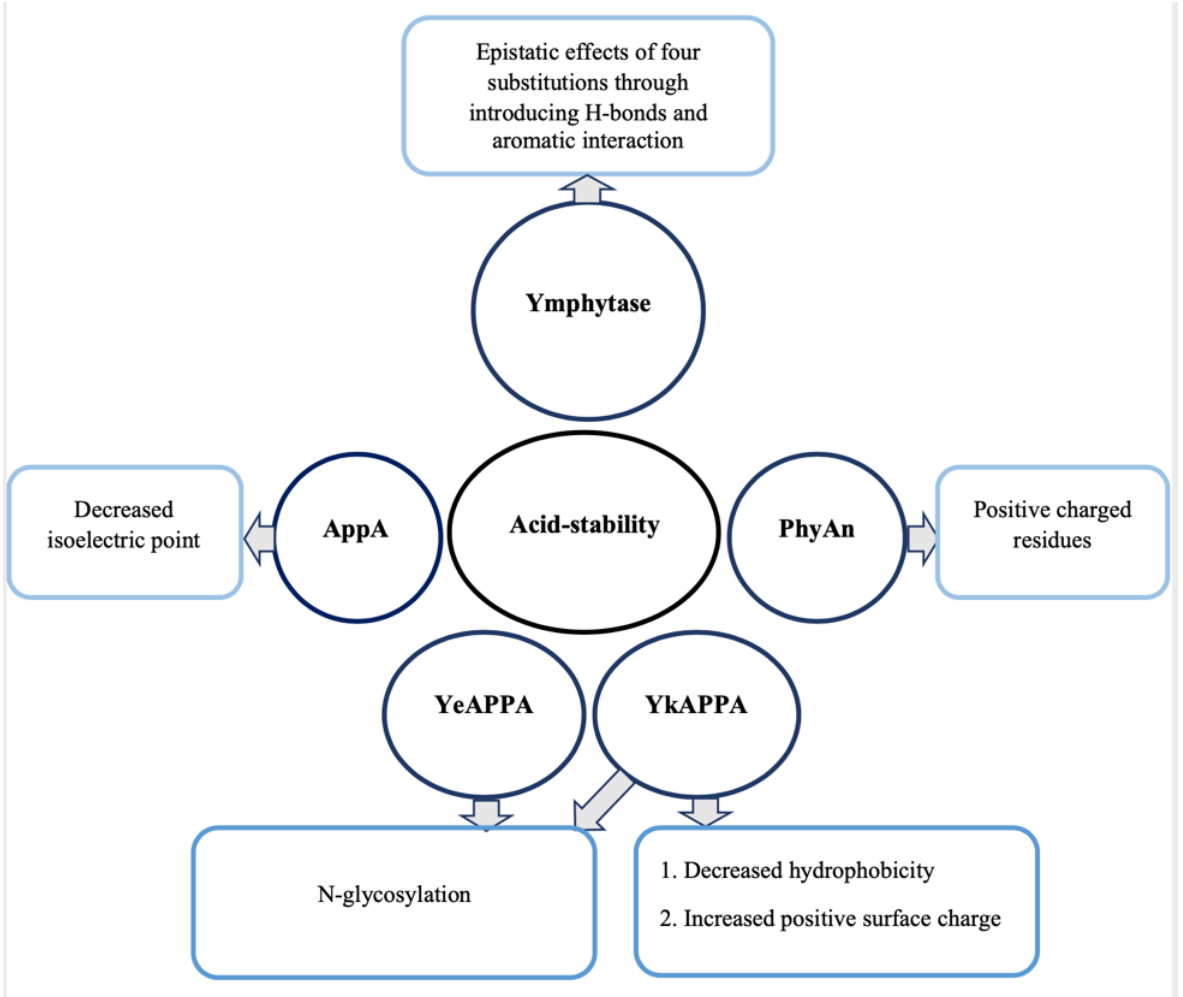

Figure 8. Contributing factors in acid stability of Ymphytase, PhyAn, YkAPPA, YeAPPA and AppA phytases. 


\subsubsection{Aspergillus Phytase}

The Y65 of a conserved active motif, RHGARYP in PhyAn, substituted to H65 demonstrated the relationship between the optimum $\mathrm{pH}$ of PhyAn and positively charged residues in the amino acid site, as shown in Figure 9. Substitution $\mathrm{Y} 65 \mathrm{H}$ to Aspergillus neoniger phytase exhibited a 9\% enhancement in residual activity compared to native PhyAn at $\mathrm{pH} 1$ for $1 \mathrm{~h}$. The optimum $\mathrm{pH}$ of PhyAn- $\mathrm{Y} 65 \mathrm{H}$ was shifted from 5.0 to 3.0. This suggested that the $\mathrm{pH}$ of phytases could be affected by the vicinity charged residue at the active site. Structural analysis revealed that both $\mathrm{Y} 65$ and $\mathrm{H} 65$ performed similar interactions (amide-Pi stacked interaction, Pi-sigma interaction, hydrogen bond) with the surrounding residues non-covalently, as shown in Figure 9B,C. This substitution had no impact on tertiary structure, and it was postulated that positively charged histidine residue was closely related to the switching of $\mathrm{pH}$ to be more acidic [48].
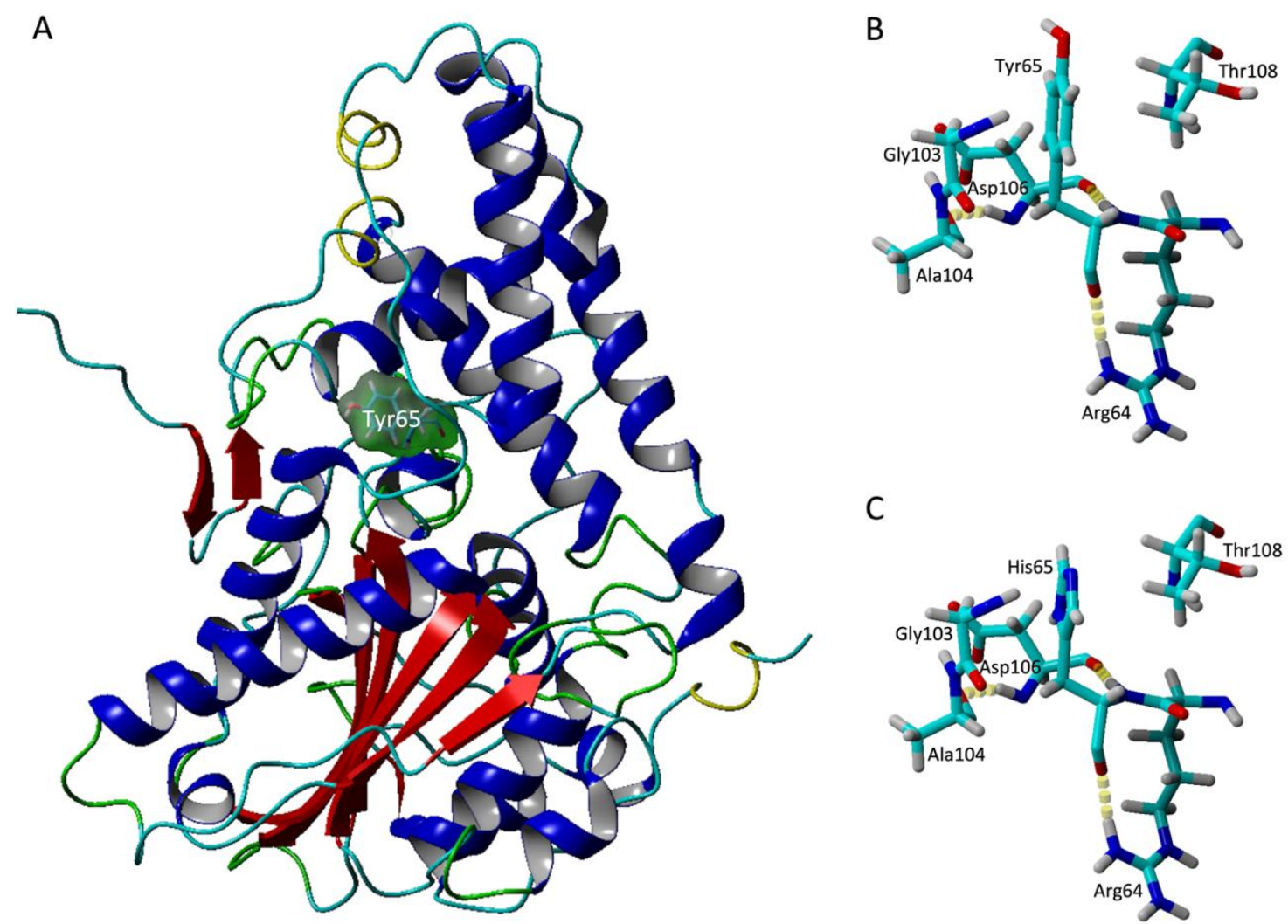

Figure 9. Mutation on Aspergillus phytase. (A): Mutation site of residue Y65 at conserved active motif, RHGARYP. (B): Interactions between Y65 and its surrounding residues. (C): Interactions between H65 and its surrounding residues.

\subsubsection{Escherichia coli Phytase}

The substitution of K24 on Escherichia coli AppA phytase to Glu retained more than $90 \%$ of its initial activity at a $\mathrm{pH}$ range of 3.0-8.0 for $2 \mathrm{~h}$. The K24E mutant was situated on the surface of the pocket edge and adjacent to the active center site. The substituting of Lys $\left(\mathrm{pK}_{\mathrm{R}} \sim 9.74\right)$ with Glu $\left(\mathrm{pK} \mathrm{R}_{\mathrm{R}} \sim 3.22\right)$ shifted the optimum $\mathrm{pH}$ from 4.5 to 4 [32].

\subsubsection{Yersinia Phytases}

A quadruple Omni1 mutant, derived from Yersinia mollaretii phytase, including D52E, K139T, G187S and V298F, showed a 2.3-fold improvement in $\mathrm{pH}$ stability compared to that of the native Yersinia mollaretii phytase at $\mathrm{pH}$ 2.8. The substitution of V298F improved phytase stability through introducing aromatic-aromatic interactions with F420. Substitution of G187S introduced H-bonds with 
the neighboring loop. A H-bond was formed between the side-chain of the D52E substitution with the backbone atom of Y197. A side chain-side chain H-bond was formed between substitution K139T and D137. Substitutions D52E, K139T, G187S and V298F were located on the neighboring active site loop, phytase surface, $\alpha$-domain and $\alpha / \beta$ domain, respectively. The enhanced $\mathrm{pH}$ stability of Omni1 could only have arisen from the synergistic effects of the substitutions [41].

N-glycosylated mutants YeAPPA-A200S, with (NFS198-200) N-glycosylation site and YeAPPADMK397-399NLT, indicated 59.9 and 70.8\% enhancements in residual activity over that of the YeAPPA (phytase from Yersinia enterocolitica) at pH 2.0 for $2 \mathrm{~h}$, respectively. N-glycosylated YkAPPA (phytase from Yersinia kristensenii) and YkAPPA-D397N/K399T showed increased acid stability compared to the $\mathrm{N}$-deglycosylated mutant. These findings suggested that glycosylation not only conferred improved thermostability to phytases, but also pH activity [43]. YkAPPA-E226H and YkAPPA-F89S/E226H retained $27.3 \%$ enhancements in residual activities at a $\mathrm{pH}$ range of 1.0-10.0 over those of the YkAPPA and YkAPPA-F89S. Thus, Histidine was an important factor in acid stability through decreasing the number of hydrophobic methylene groups in $\mathrm{E} 226 \mathrm{H}$, which extended the positive surface charge of E226H [44].

\subsection{Improved Proteolytic Stability}

Two enzymes-pepsin and trypsin—with proteolytic activities in the digestive tract of poultry are considered as barriers to proteins and enzymes that are added to industrial chicken diet. Pepsin cleavage sites are at the $\mathrm{N}$-terminals of the aromatic amino acids tryptophan, tyrosine and phenylalanine, while the trypsin cleavage sites are at the C-terminals of arginy1 and Lysy1 peptide bonds [49]. In this section, the contributing factors, as shown in Figure 10, in proteolytic stability are described, as shown in Table 3.

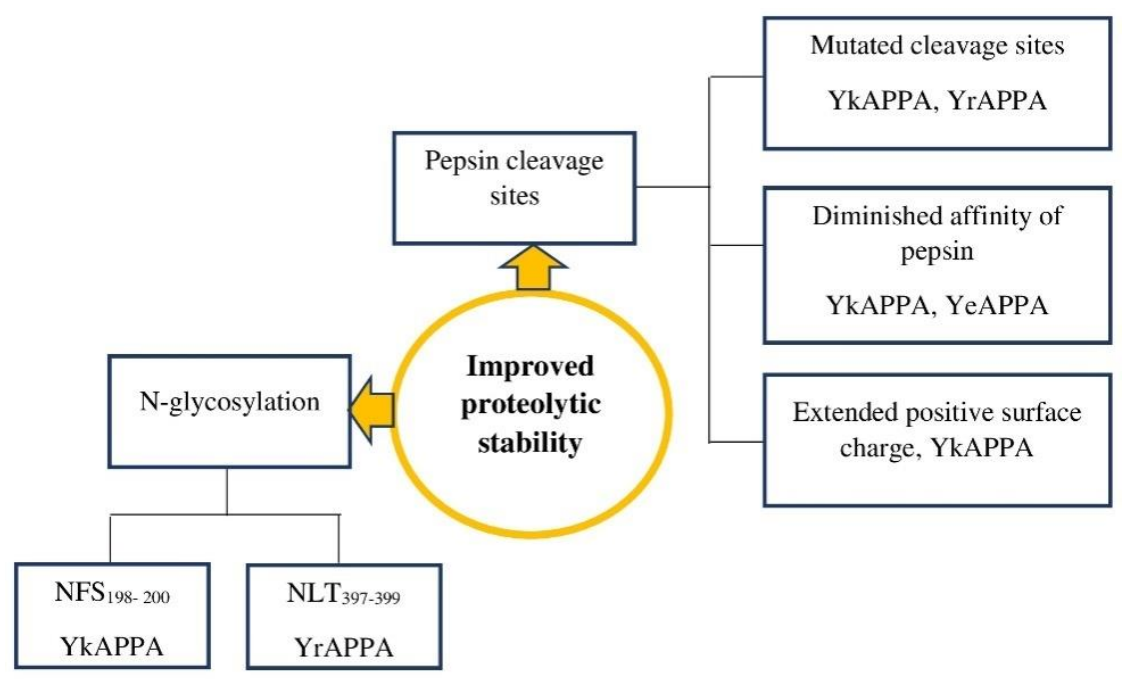

Figure 10. Proteolytic stability factors in YkAPPA, YeAPPA and YrAPPA phytases.

Table 3. Factors contributing to proteolytic stability.

\begin{tabular}{|c|c|c|c|c|c|c|}
\hline No. & Source & Phytase & Approaches & Location of Mutation & $\begin{array}{l}\text { Contributing Factors in } \\
\text { Proteolytic Stability }\end{array}$ & References \\
\hline 1 & $\begin{array}{l}\text { Yersinia kristensenii, } \\
\text { Yersinia rohdei }\end{array}$ & $\begin{array}{l}\text { YkAPPA, } \\
\text { YrAPPA }\end{array}$ & $\begin{array}{l}\text { Site-directed } \\
\text { mutagenesis }\end{array}$ & $\begin{array}{c}\text { Vicinity of } \\
\text { N-glycosylation motifs }\end{array}$ & Substituting pepsin cleavage sites & Niu et al., 2016 \\
\hline 2 & Yersinia kristensenii & YkAPPA & $\begin{array}{l}\text { Site-directed } \\
\text { mutagenesis }\end{array}$ & Phytase surface & $\begin{array}{c}\text { Remove hydrophobic } \\
\text { interactions phenyl F group and } \\
\text { pepsin, increased positive surface } \\
\text { charge }\end{array}$ & Niu et al., 2017 \\
\hline 3 & $\begin{array}{l}\text { Yersinia kristensenii, } \\
\text { Yersinia enterocolitica }\end{array}$ & $\begin{array}{l}\text { YkAPPA, } \\
\text { YeAPPA }\end{array}$ & $\begin{array}{l}\text { Site-directed } \\
\text { mutagenesis }\end{array}$ & Phytase surface & Reducing pepsin cleavage sites & Niu et al., 2017 \\
\hline 4 & Escherichia coli & AppA & $\begin{array}{l}\text { Site-directed } \\
\text { mutagenesis }\end{array}$ & Loops & $\begin{array}{l}\text { Substitution of trypsin cleavage } \\
\text { sites, H-bond, N-glycosylation }\end{array}$ & Wang et al., 2018 \\
\hline
\end{tabular}




\subsubsection{Yersinia Phytases}

The resistance of phytases against pepsin digestion is an additional feature as feed enzymes. Pepsin stability was enhanced in non-glycosylated YkAPPA phytase (Yersinia kristensenii) and YrAPPA phytase (Yersinia rohdei) by substituting the cleavage sites L197V and L396V that were located adjacent to the N-glycosylation sites NFS $198-200$ and NLT $_{397-399}$, respectively. N-glycan linkage at N198 and N397 gave rise to steric hindrance between pepsin and the pepsin cleavage sites. As a result of the introduction of $\mathrm{N}$-glycosylation sites to Yersinia phytases, pepsin stability was increased. The homology modeling analysis of three Yersinia phytases demonstrated that the N-linked glycosylation motifs, $\mathrm{NFS}_{198-200}$ and $\mathrm{NLT}_{397-399}$, in YkAPPA and YrAPPA, respectively, were located on the phytase surface [43]. Under the incubation of pepsin for $2 \mathrm{~h}$, the YkAPPA-F89S/E226H mutant from Yersinia kristensenii showed 36 and $9.6 \%$ enhancements in pepsin stability over the YkAPPA-F89S and YkAPPA-E226H mutants, respectively. It was concluded that the pepsin resistance of the double mutant was as a result of the synergistic effect between $\mathrm{S} 89$ and H226. Hydrophobic interactions between pepsin and the large phenyl F group were obliterated through substitution F89S, resulting in the diminished affinity of pepsin toward phytase. Substitution E226H also gave rise to a decrease in the number of hydrophobic methylene groups in E226H, which increased the positive surface charge of E226H, thereby enhancing pepsin stability in phytase [44].

The L99, L162 and E230 pepsin cleavage sites located on the surface of YeAPPA phytase (Y. enterocolitica) and YkAPPA phytase (Yersinia kristensenii) were replaced with smaller side-chain amino acids. Double mutant YkAPPA-L99A/L162G and triple mutant YkAPPA-L99A/L162G/E230G showed around 3.5- and 25-fold improvements in proteolytic half-life than native YkAPPA under pepsin treatment at $37^{\circ} \mathrm{C}$ for $2 \mathrm{~h}$, respectively. Mutants YeAPPA-L99A/L162G/L230G and YeAPPA-E230G indicated around 0.44 - and 0.17-fold enhancements in proteolytic half-life than native YeAPPA under pepsin treatment at $37^{\circ} \mathrm{C}$ for $2 \mathrm{~h}$, respectively. Pepsin stability could be obtained through decreasing the number of pepsin cleavage sites in phytase. The replacement of L99, L162 and E230 with smaller side chains gave rise to the diminishing of the inner space in the structure and could also open a space between phytase and pepsin. So, improved pepsin resistance was acquired through diminishing the affinity of pepsin to phytase [50].

\subsubsection{Escherichia coli Phytase}

The trypsin stability of mutant AppA-M6 was increased by 60 and $20.8 \%$ over that of the AppA-WT at trypsin/phytase ratios of 0.3 and 2.1, respectively. Six residues, including K74, K75, K180, R181, K183 and K363, with relatively high solvent accessibility scores, were detected as cleavage sites for trypsin, which were located on the distinct surface loops. These resides were substituted with other polar amino acids. A strong new H-bond was introduced between D74 and Q75. Two H-bonds were introduced between N180 and N176, which were situated on the loop and adjacent to the $\alpha$-helix areas, respectively. These two H-bonds might have stabilized the interaction between the $\alpha$-helix and the loop, resulting in phytase stability. Increased H-bonding was observed between N363 and E53. Three N-glycosylation positions, including N139, N204 and N317 situated at the $\alpha$-helix, $\beta$-sheet and random coil, respectively, were predicted in AppA-WT and its mutants. The expression system in Pichia pastoris brought about N-glycosylation modification at the $\mathrm{N}$ in the consensus sequence N-X-S/T. The reinforcement of the H-bond network in the loop area and N-glycosylation modification enhanced the stability of the phytase structure against trypsin [33]. 


\subsection{Improved Catalytic Efficiency and Specific Activity}

Exogenous phytase activity widely happened in the upper part of the digestive tract of poultry, including the crop, proventriculus and gizzard. Optimum activity depended on optimum $\mathrm{pH}$ and proteolytic stability in the digestive tract. Other factors, such as feed ingredient composition and age, gender and species of poultry, could also influence phytase activity for breaking down phytate in the digestive tract [5]. Recently, some teams had carried out different studies on phytases, taking into account several factors, as shown in Figure 11, from microbial sources, including Aspergillus, Escherichia coli, Bacillus and Yersinia, to improve phytase activity for improving catalytic efficiency and specific activity, as shown in Table 4.

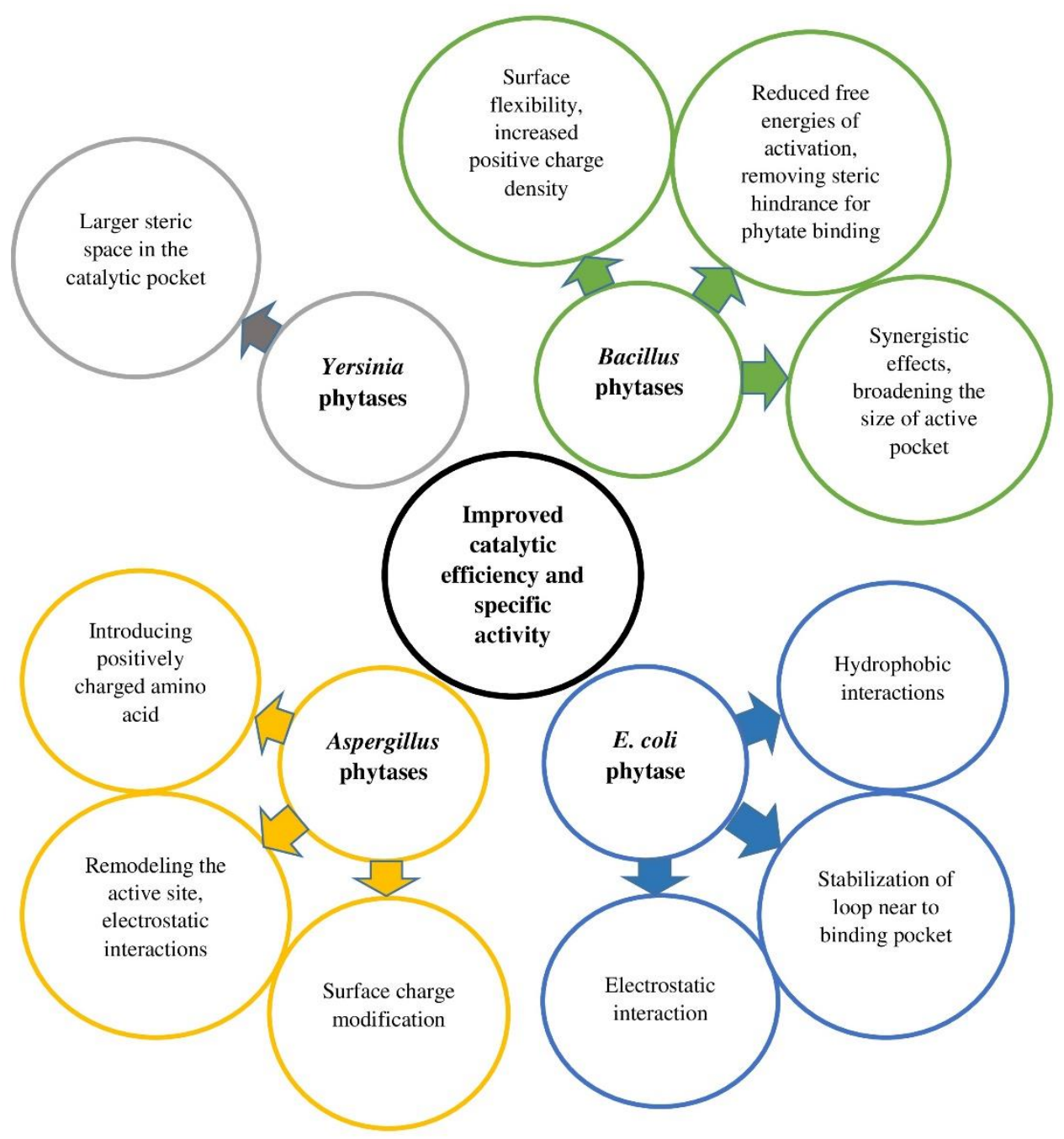

Figure 11. Contributing factors in improved catalytic efficiency and specific activity of phytases. 
Table 4. Improvements of catalytic efficiency and specific activity of various microbial phytases.

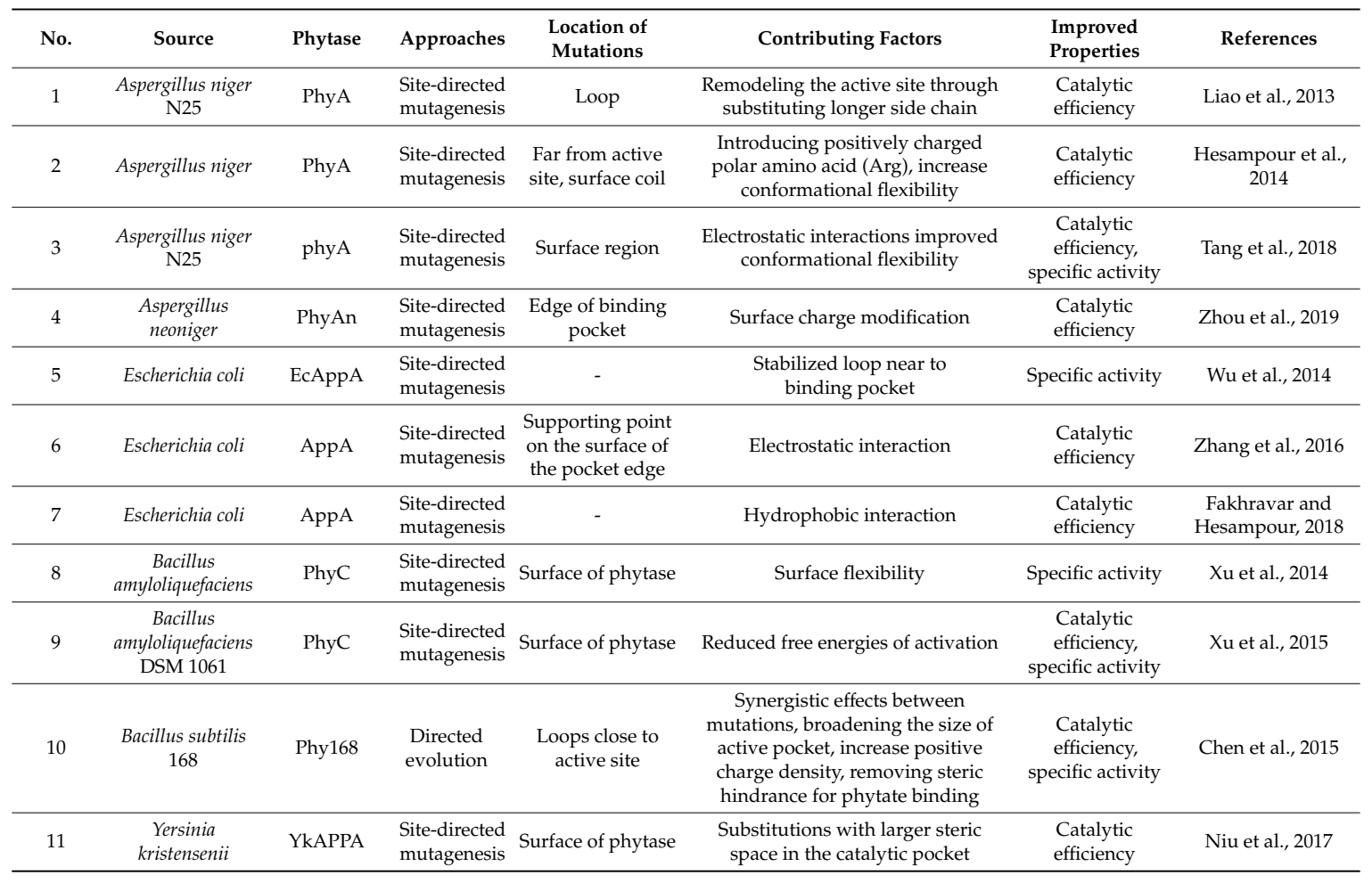

\subsubsection{Aspergillus Phytases}

Liao and his team conducted site-directed mutagenesis on PhyA phytase from Aspergillus niger N25 in order to improve catalytic efficiency and thermostability. The mutant PhyA-I44E showed a $310 \%$ enhancement in catalytic efficiency over that of the native phytase. Substituting I44E, situated at the loop of the $\alpha / \beta$ domain at the surface area, was done. Glu- 44 with a longer side chain gave rise to increased interactions between residues adjacent to the active center, resulting in an increment in catalytic efficiency through the reorganization or remodeling of the active site [19]. Another study used site-directed mutagenesis to enhance the kinetic efficiency and thermostability of PhyA from Aspergillus niger. Mutants P9 (T314S, Q315R, V62N) and P12 (S205N, S206A, T151A, T314S, Q315R) showed 34.5 and $24 \%$ enhancements in catalytic efficiencies, respectively, compared with those of the native phytase. Substitution Q315R in mutant P12 showed that the positively charged polar amino acid Arg-instead of the uncharged polar amino acid Gln—could improve catalytic efficiency. Besides, substitution V62N situated on the surface coil brought about increased catalytic efficiency through an increment in conformational flexibility [20]. Double mutant Q368E/K432R with 503,217 U/mg specific activity showed a $66 \%$ improvement in specific activity compared to PP-NP ${ }^{e p}-6 \mathrm{~A}$ with $303,715 \mathrm{U} / \mathrm{mg}$ specific activity. Mutant PP-NPep-6A had been obtained through Error-Prone PCR of the phyA ${ }^{\mathrm{m}}$ gene from Aspergillus niger N25 [24]. Substitutions of Q368E and K432R indicated remarkable differences in electrostatic interactions, so enzyme performance could be affected by both substitutions as a result of the modification of electrostatic interactions. Due to substituting amino acid Q368 with the negatively charged amino acid Glu on the surface areas, the interaction between the charged microenvironment and the spatially neighboring substrate binding site was altered. This increased the accessibility of the active site for the substrate and also enhanced catalytic efficiency. Electrostatic interactions between two adjacent residues, Q368E and F376Y, improved conformational flexibility [25].

The catalytic efficiency of mutant E79K/E80K was increased by $86 \%$ over that of the native PhyAn (Aspergillus neoniger phytase). Increased substrate affinity was also found in this double mutant. The E79 and E80 substitution sites were situated on the edge of the binding pocket. Based on docking analysis, there was no non-covalent interaction between the E79 and E80 substitution sites and the 
substrate, thereby specific activity was increased without direct interaction with the substrate by these substitutions. The improved affinity of phytate with negative charge to the binding pocket could have arisen from changing the charge adjacent to the binding pocket from negative to positive, due to substitutions. Hence, surface charge modification brought about the improved catalytic efficiency [48].

\subsubsection{Escherichia coli Phytase}

Based on the CbAppA phytase from Citrobacter, mutation V89T was introduced to EcAppA phytase from Escherichia coli. The V89T mutant indicated a 17.5\% enhancement in specific activity compared to that of the native EcAppA. Structural analysis of V89T revealed that the increased specific activity was a result of a H-bond interaction between T89 and S119. The stabilization of the loop114-121 as a result of T89-S119 interaction increased the catalytic efficiency because the stabilized loop was near to the binding pocket. Therefore, the specific activity of the enzyme could be affected through changing residues or structural properties that were located adjacent to the binding pocket. Substitution V89T

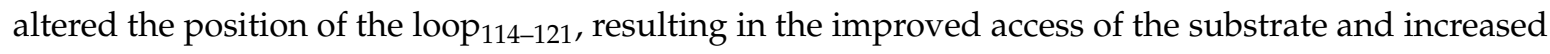
specific activity. Consequently, structural properties and residues around the active site with indirect interactions to the substrate showed remarkable effects on enzyme activity [30].

In comparison with native AppA phytase from Escherichia coli, mutant K24E showed a $0.13 \%$ decrement in $\mathrm{K}_{\mathrm{m}}$ and a $25 \%$ increment in $\mathrm{V}_{\max }$. The $\mathrm{K} 24 \mathrm{E}$ was situated on the surface of the pocket edge adjacent to the active site. The substituting of Lys-24 to Glu with a smaller side chain decreased spatial hindrance, as shown in Figure 12. The replacement of positively charged Lys-24 to negatively charged Glu could elevate electrostatic interaction between substrate and enzyme. So, K24E brought about elevated affinity between enzyme and substrate, and also increased catalytic efficiency [32]. Mutant S392F showed a 25.6\% enhancement in catalytic efficiency over that of the native phytase. Structural comparison between S392F and native phytase revealed that substituting Ser-392 with Phe introduced two new hydrophobic interactions with Trp-347 [34].

A
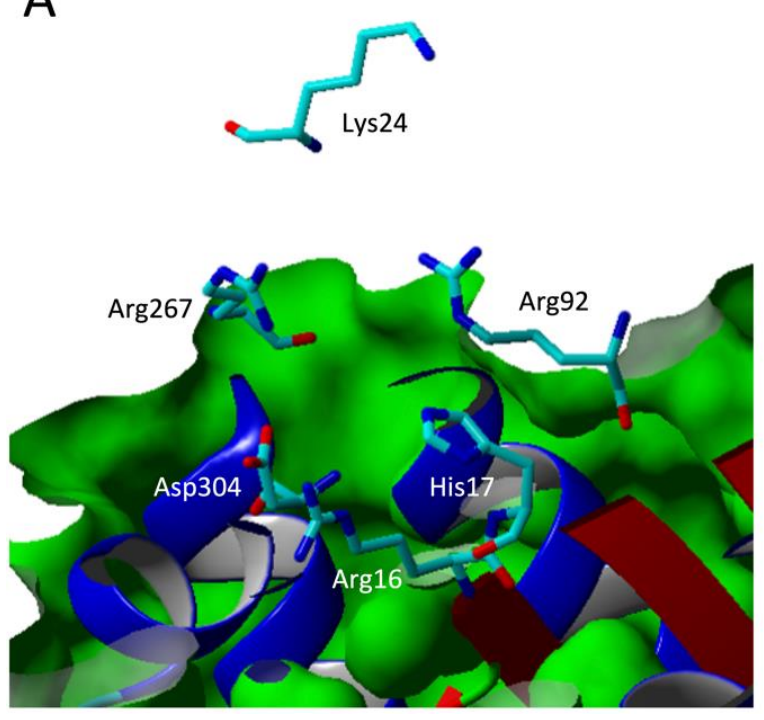

B
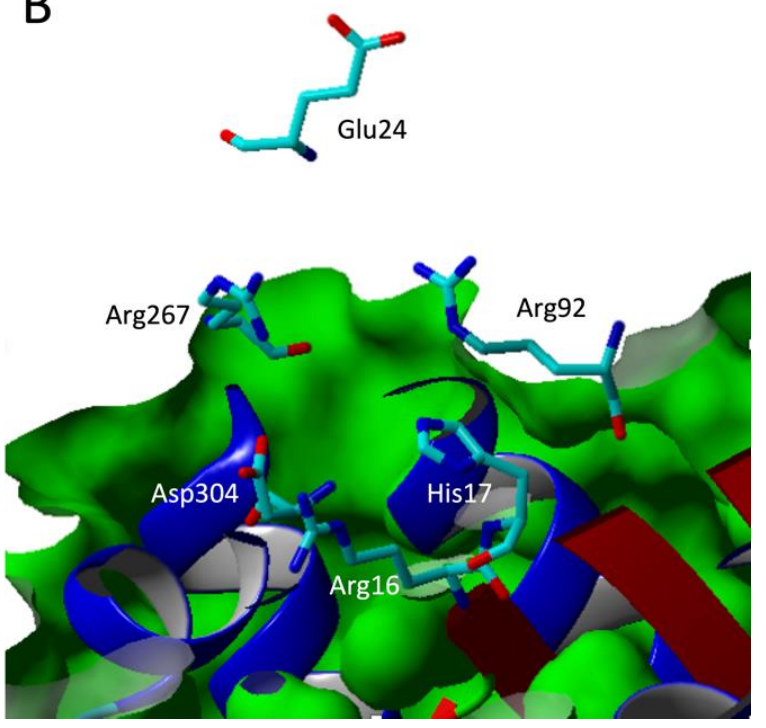

Figure 12. Mutation on phytase from Escherichia coli. (A): Location of residue K24 at surface of the pocket edge. (B): Substitution K24E. Part of the secondary structures was cut to reveal location of residues near the binding pocket using YASARA Structure software.

\subsubsection{Bacillus Phytases}

Double mutations D148E/H149R were introduced to phyC from Bacillus amyloliquefaciens. D148E/H149R showed a 2.19\% enhancement in specific activity compared to PhyC. Structural analysis revealed that D148 and H149 were located on the surface of the enzyme. It was concluded that 
the facilitated binding of the substrate to the active site could be a result of the surface flexibility of the mutant [37]. Introducing mutations D148E and S197E to Bacillus amyloliquefaciens, DSM 1061 phytase enhanced specific activity by 35 and $13 \%$, respectively. These mutations also increased catalytic efficiency by 1.5- and 1.25-times, respectively. D148 and S197 were semi-conserved residues located on the surface, but far from the active site. Based on kinetic analysis, the increments in the catalytic efficiencies of D148E and S197E were mostly derived from the improvement of $\mathrm{k}_{\mathrm{cat}}$. The free energies of activation in both of the substitutions were decreased as a result of increased $\mathrm{k}_{\mathrm{cat}}$ [38].

The specific activities of the D24G, S51A, D24G/K265N and D24G/K70R/K111E/N121S mutants at $60{ }^{\circ} \mathrm{C}$ and $\mathrm{pH} 7$ were increased by $29.7 \%, 13.5 \%, 42.7 \%$ and $42.8 \%$, respectively, over those of phy168 from Bacillus subtilis 168 . These mutants showed better specific activity enhancements of $76.6 \%, 79.5 \%, 84.2 \%$ and $121.1 \%$ at $\mathrm{pH} 4.5$ and $37^{\circ} \mathrm{C}$, respectively. Mutants $\mathrm{D} 24 \mathrm{G}, \mathrm{D} 24 \mathrm{G} / \mathrm{K} 265 \mathrm{~N}$ and $\mathrm{D} 24 \mathrm{G} / \mathrm{K} 70 \mathrm{R} / \mathrm{K} 111 \mathrm{E} / \mathrm{N} 121 \mathrm{~S}$ showed $132 \%, 110 \%$ and $131 \%$ improvements in catalytic efficiency at pH7, and also $98.0 \%, 114.5 \%$ and $163.3 \%$ improvements, respectively, at $\mathrm{pH} 4.5$ over those of the native phytase. Two single mutants D24G and S51A showed $40.3 \%$ and $24.5 \%$ enhancements in specific activity at $\mathrm{pH} 7.0$ and $37^{\circ} \mathrm{C}$, and $76.6 \%$ and $79.5 \%$ enhancements at $\mathrm{pH} 4.5$ and $37^{\circ} \mathrm{C}$, respectively. The specific activities of the double mutants D24G/K265E and S51A/K265E were increased by $50 \%$ and $32.6 \%$ at $\mathrm{pH} 7$ and $37^{\circ} \mathrm{C}$, and $137.4 \%$ and $131.6 \%$ enhancements at $\mathrm{pH} 4.5$ and $37^{\circ} \mathrm{C}$ over those of the native phytase, respectively. These enhancements in specific activities of the double mutants over those of the single mutants were attributed to synergistic effects between the mutations. Based on structural analysis, the three single substitutions, D24G, S51A and K70R, on the loops of the first two blades and neighboring active sites, as shown in Figure 13, significantly improved the specific activity of phy 168 phytase from Bacillus subtilis 168. Substitution D24G removed the steric hindrance for phytate binding and broadened the size of the active pocket. The greater specific activity of D24G/K70R/K111E/N121S compared to D24G and D24G/K265N in acidic $\mathrm{pH}$ was a result of the increment in positive charge density through substitution K70R [40].

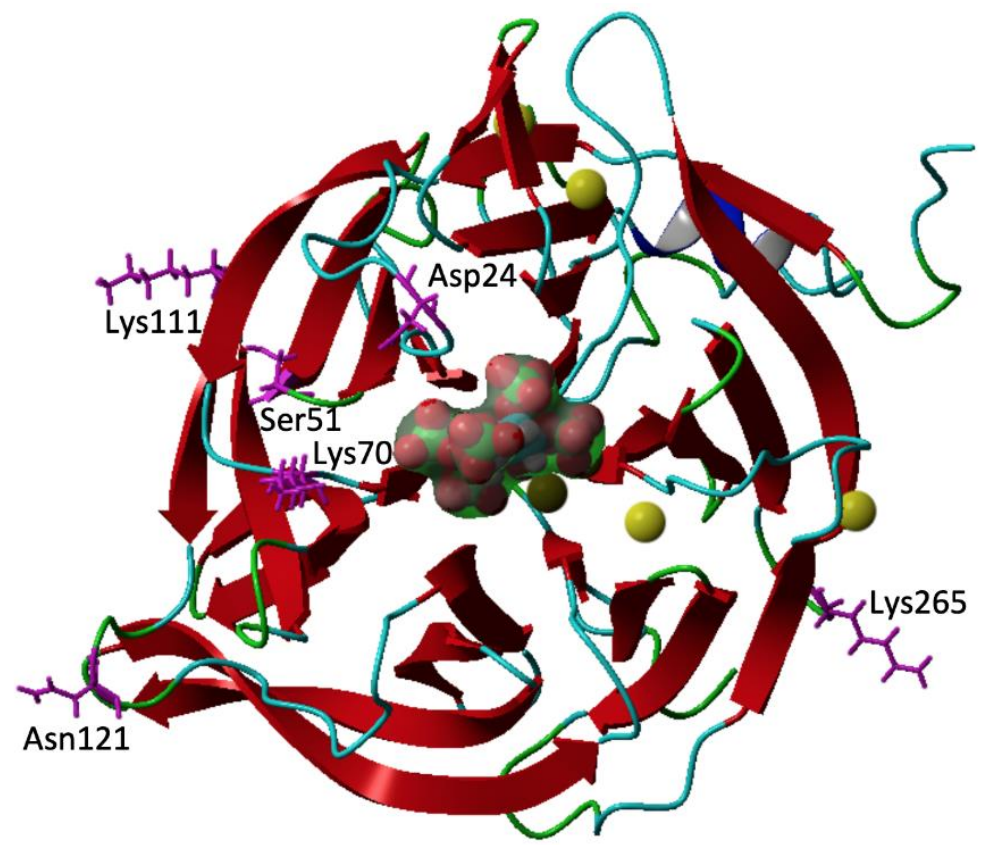

Figure 13. The mutation sites D24, S51, K70, K111, N121 and K265 of Bacillus subtilis phytase surrounding the bound phytate. 


\subsubsection{Yersinia Phytases}

Mutant YkAPPA-E230G from Yersinia kristensenii and mutant YeAPPA-E230G from Yersinia enterocolitica showed 2.1- and 2.5-fold enhancements in catalytic efficiency over those of the wild-types. However, substitution L162G led to enhanced catalytic efficiency by less than 1.9-fold in YkAPPA and YeAPPA, respectively. The number of hydrogen bonds in the catalytic centers of substitutions E230G and L162G were 3- and 6-times higher over that of YkAPPA, respectively. The substitutions were on the surfaces of the phytases. The flexibility of the active residue was decreased as a result of substitutions E230G and L162G, which had larger steric space in the catalytic pocket, thereby facilitating substrate entry and binding [50].

\section{Conclusions}

In order to construct manipulated phytases with improved properties, analyzing the structure based on computational methods is indispensable. For thermostability, the most important factors are the rigidifying of the flexible regions and introducing additional interactions. Loops are found to be the most thermolabile regions and usually the unfolding of phytase is initiated from loops at high temperatures and extended to adjacent regions. One of the practical approaches to design thermostable phytase can be integrative structural comparisons of homologous phytases and computational simulations in order to find critical points of mutations and interactions. Substituting aromatic and hydrophobic interactions can reduce the structural flexibility of the enzyme. Modifications of the protein surface residues can improve electrostatic interactions and decrease protein flexibility (entropy). Charged amino acids are low in thermophilic proteins. Enhanced thermostability gives rise to a reduction in activity. The distance from mutation site to active site should be more than $10 \AA$ to avoid hindrance in the substrate-binding motif. For acid stability, extending the positively charged surface can improve it and some of the studies introduced mutations close to the active site. Additionally, glycosylation and using amino acids with low isoelectric points can improve acid stability. Some criteria are involved to increase the specific activity and catalytic efficiency of phytase, including the remodeling and reorganization of the active site through introducing mutations close to the active site, shifting charge adjacent to the binding pocket from negative to positive and removing steric hindrance for binding. For proteolytic stability, decreasing pepsin cleavage sites through mutation and employing steric hindrance between pepsin and pepsin cleavage sites are some practical approaches.

Author Contributions: Conceptualization, T.C.L. and N.G.N.; writing-original draft preparation, T.C.L. and N.G.N.; drawing, T.C.L. and N.G.N.; writing-review and editing, T.C.L., N.G.N., Y.M.N., F.M.S., S.N.O. and R.N.Z.R.A.R. All authors have read and agreed to the published version of the manuscript.

Funding: The authors wish to thank the Research Management Center, Office of The Deputy Vice Chancellor (Research \& Innovation) for the support of publication fee and proof reading service cost.

Conflicts of Interest: The authors declare no conflicts of interest.

\section{References}

1. Sparvoli, F.; Cominelli, E. Seed biofortification and phytic acid reduction: A conflict of interest for the plant? Plants 2015, 4, 728-755. [CrossRef] [PubMed]

2. Kaushik, G. Applied Environmental Biotechnology: Present Scenario and Future Trends; Springer: New Delhi, India, 2015; pp. 1-167. [CrossRef]

3. Gupta, R.K.; Gangoliya, S.S. Reduction of phytic acid and enhancement of bioavailable micronutrients in food grains. J. Food Sci. Technol. 2015, 52, 676-684. [CrossRef] [PubMed]

4. El-Hack, M.E.A.; Alagawany, M.; Arif, M.; Emam, M.; Saeed, M.; Arain, M.A.; Siyal, F.A.; Patra, A.; Elnesr, S.S.; Khan, R.U. The uses of microbial phytase as a feed additive in poultry nutrition-A review. Ann. Anim. Sci. 2018, 18, 639-658. [CrossRef] 
5. Dersjant-Li, Y.; Awati, A.; Schulze, H.; Partridge, G. Phytase in non-ruminant animal nutrition: A critical review on phytase activities in the gastrointestinal tract and influencing factors. J. Sci. Food Agric. 2015, 95, 878-896. [CrossRef] [PubMed]

6. Afinah, S.; Yazid, A.M.; Anis Shobirin, M.H.; Shuhaimi, M. Review Article Phytase: Application in food industry. Int. Food Res. J. 2010, 17, 13-21.

7. Lim, D.; Golovan, S.; Forsberg, C.W.; Jia, Z. Crystal structures of Escherichia coli phytase and its complex with phytate. Nat. Struct. Biol. 2000, 7, 108-113. [CrossRef]

8. Shin, S.; Ha, N.C.; Oh, B.C.; Oh, T.K.; Oh, B.H. Enzyme mechanism and catalytic property of $\beta$ propeller phytase. Structure 2001, 9, 851-858. [CrossRef]

9. Kumar, A.; Chanderman, A.; Makolomakwa, M.; Perumal, K.; Singh, S. Microbial production of phytases for combating environmental phosphate pollution and other diverse applications. Crit. Rev. Environ. Sci. Technol. 2016, 46, 556-591. [CrossRef]

10. Madsen, C.K.; Brinch-pedersen, H. Molecular Advances on Phytases in Barley and Wheat. Int. J. Mol. Sci. 2019, 20, 2459. [CrossRef]

11. Troxell, B.; Petri, N.; Daron, C.; Pereira, R.; Mendoza, M.; Hassan, H.M.; Koci, M.D. Poultry body temperature contributes to invasion control through reduced expression of Salmonella pathogenicity island 1 genes in Salmonella enterica serovars typhimurium and enteritidis. Appl. Environ. Microbiol. 2015, 81, 8192-8201. [CrossRef]

12. Outchkourov, N.; Petkov, S. Phytases for Feed Applications. In Industrial Enzyme Applications; Vogel, A., Ed.; Wiley-VCH: Weinheim, Germany, 2019; pp. 255-285. [CrossRef]

13. Mrudula Vasudevan, U.; Jaiswal, A.K.; Krishna, S.; Pandey, A. Thermostable phytase in feed and fuel industries. Bioresour. Technol. 2019, 278, 400-407. [CrossRef] [PubMed]

14. Abdollahi, M.R.; Ravindran, V.; Svihus, B. Pelleting of broiler diets: An overview with emphasis on pellet quality and nutritional value. Anim. Feed Sci. Technol. 2013, 179, 1-23. [CrossRef]

15. Modarres, H.P.; Mofrad, M.R.; Sanati-Nezhad, A. Protein thermostability engineering. RSC Adv. 2016, 6, 115252-115270. [CrossRef]

16. Jimenez, A.; Miriam, R.; Merino, V.F. Tailoring Proteins to Re-Evolve Nature: A Short Review. Mol. Biotechnol. 2018, 60, 946-974. [CrossRef]

17. Liu, S.Y.; Selle, P.H.; Cowieson, A.J. Influence of conditioning temperatures on amino acid digestibility coefficients at four small intestinal sites and their dynamics with starch and nitrogen digestion in sorghum-based broiler diets. Anim. Feed Sci. Technol. 2013, 185, 85-93. [CrossRef]

18. Noorbatcha, I.A.; Sultan, A.M.; Salleh, H.M.; Amid, A. Understanding thermostability factors of aspergillus niger PhyA phytase: A molecular dynamics study. Protein J. 2013, 32, 309-316. [CrossRef]

19. Liao, Y.; Li, C.M.; Chen, H.; Wu, Q.; Shan, Z.; Han, X.Y. Site-directed mutagenesis improves the thermostability and catalytic efficiency of aspergillus niger N25 phytase mutated by I44E and T252R. Appl. Biochem. Biotechnol. 2013, 171, 900-915. [CrossRef]

20. Hesampour, A.; Ehsan, S.; Siadat, R. Enhancement of Thermostability and Kinetic Efficiency of Aspergillus niger PhyA Phytase by Site-Directed Mutagenesis. Appl. Biochem. Biotechnol. 2014. [CrossRef]

21. Fonseca-Maldonado, R.; Maller, A.; Bonneil, E.; Thibault, P.; Botelho-Machado, C.; Ward, R.J.; Polizeli, M.D.L.T.D.M. Biochemical properties of glycosylation and characterization of a histidine acid phosphatase (phytase) expressed in Pichia pastoris. Protein Expr. Purif. 2014, 99, 43-49. [CrossRef]

22. Kumar, K.; Patel, K.; Agrawal, D.C.; Khire, J.M. Insights into the unfolding pathway and identification of thermally sensitive regions of phytase from Aspergillus niger by molecular dynamics simulations. J. Mol. Model. 2015, 21. [CrossRef]

23. Han, N.; Miao, H.; Yu, T.; Xu, B.; Yang, Y.; Wu, Q.; Zhang, R. Enhancing thermal tolerance of Aspergillus niger PhyA phytase directed by structural comparison and computational simulation. BMC Biotechnol. 2018, 18, 1-8. [CrossRef]

24. Liao, Y.; Zeng, M.; Wu, Z.F.; Chen, H.; Wang, H.N.; Wu, Q.; Shan, Z.; Han, X.Y. Improving Phytase Enzyme Activity in a Recombinant phyA Mutant Phytase from Aspergillus niger N25 by Error-Prone PCR. Appl. Biochem. Biotechnol. 2012, 166, 549-562. [CrossRef] [PubMed]

25. Tang, Z.; Jin, W.; Sun, R.; Liao, Y.; Zhen, T.; Chen, H.; Wu, Q.; Gou, L. Improved thermostability and enzyme activity of a recombinant phyA mutant phytase from Aspergillus niger N25 by directed evolution and sitedirected mutagenesis. Enzyme Microb. Technol. 2018, 108, 74-81. [CrossRef] [PubMed] 
26. Fei, B.; Xu, H.; Cao, Y.; Ma, S. A multi-factors rational design strategy for enhancing the thermostability of Escherichia coli AppA phytase. J. Ind. Microbiol. Biotechnol. 2013, 40, 457-464. [CrossRef] [PubMed]

27. Fei, B.; Xu, H.; Zhang, F.; Li, X.; Ma, S.; Cao, Y.; Xie, J.; Qiao, D.; Cao, Y. Relationship between Escherichia coli AppA phytase's thermostability and salt bridges. J. Biosci. Bioeng. 2013, 115, 623-627. [CrossRef] [PubMed]

28. Fei, B.; Cao, Y.; Xu, H.; Li, X.; Song, T.; Fei, Z.; Qiao, D.; Cao, Y. AppA C-terminal plays an important role in its thermostability in escherichia coli. Curr. Microbiol. 2013, 66, 374-378. [CrossRef]

29. Xi, M.Y.; Wei, W. Improving the thermostability of Escherichia coli phytase, appA, by enhancement of glycosylation. Biotechnol. Lett. 2013, 35, 1669-1676. [CrossRef]

30. Wu, T.H.; Chen, C.C.; Cheng, Y.S.; Ko, T.P.; Lin, C.Y.; Lai, H.L.; Huang, T.Y.; Liu, J.R.; Guo, R.T. Improving specific activity and thermostability of Escherichia coli phytase by structure-based rational design. J. Biotechnol. 2014, 175, 1-6. [CrossRef]

31. Wang, X.; Yao, M.; Yang, B.; Fu, Y.; Hu, F.; Liang, A. Enzymology and thermal stability of phytase appA mutants. RSC Adv. 2015, 5, 43863-43872. [CrossRef]

32. Zhang, J.; Liu, Y.; Gao, S.; Zhu, L.; Li, W.; Tian, X.; Liu, Y. Site-directed mutagenesis and thermal stability analysis of phytase from Escherichia coli. Biosci. Biotechnol. Res. Commun. 2016, 9, 357-365. [CrossRef]

33. Wang, X.; Du, J.; Zhang, Z.Y.; Fu, Y.J.; Wang, W.M.; Liang, A.H. A rational design to enhance the resistance of Escherichia coli phytase appA to trypsin. Appl. Microbiol. Biotechnol. 2018. [CrossRef] [PubMed]

34. Fakhravar, A.; Hesampour, A. Rational design-based engineering of a thermostable phytase by site- directed mutagenesis. Mol. Biol. Rep. 2018. [CrossRef] [PubMed]

35. Li, J.; Li, X.; Gai, Y.; Sun, Y.; Zhang, D. Evolution of E. coli Phytase for Increased Thermostability Guided by Rational Parameters. J. Microbiol. Biotechnol. 2019, 29, 419-428. [CrossRef]

36. Farhat-Khemakhem, A.; Ali, M.B.; Boukhris, I.; Khemakhem, B.; Maguin, E.; Bejar, S.; Chouayekh, H. Crucial role of Pro 257 in the thermostability of Bacillus phytases: Biochemical and structural investigation. Int. J. Biol. Macromol. 2013, 54, 9-15. [CrossRef]

37. Xu, W.; Wang, Z.; Shao, R. Site-directed Mutagenesis of a Neutral Phytase from Bacillus amyloliquefaciens: Influencing Activity and Stability. Adv. Mater. Res. 2014, 1034, 271-278. [CrossRef]

38. Xu, W.; Shao, R.; Wang, Z.; Yan, X. Improving the Neutral Phytase Activity from Bacillus amyloliquefaciens DSM 1061 by Site-Directed Mutagenesis. Appl. Biochem. Biotechnol. 2015. [CrossRef] [PubMed]

39. Boukhris, I.; Farhat-khemakhem, A.; Blibech, M.; Bouchaala, K.; Chouayekh, H. Characterization of an extremely salt-tolerant and thermostable phytase from Bacillus amyloliquefaciens US573. Int. J. Biol. Macromol. 2015, 80, 581-587. [CrossRef]

40. Chen, W.; Ye, L.; Guo, F.; Lv, Y.; Yu, H. Enhanced activity of an alkaline phytase from Bacillus subtilis 168 in acidic and neutral environments by directed evolution. Biochem. Eng. J. 2015, 98, 137-143. [CrossRef]

41. Shivange, A.V.; Dennig, A.; Schwaneberg, U. Multi-site saturation by OmniChange yields a pH- and thermally improved phytase. J. Biotechnol. 2014, 170, 68-72. [CrossRef] [PubMed]

42. Shivange, A.V.; Roccatano, D.; Schwaneberg, U. Iterative key-residues interrogation of a phytase with thermostability increasing substitutions identified in directed evolution. Appl. Microbiol. Biotechnol. 2016, 100, 227-242. [CrossRef]

43. Niu, C.; Luo, H.; Shi, P.; Huang, H.; Wang, Y.; Yang, P.; Yao, B. N-glycosylation improves the pepsin resistance of histidine acid phosphatase phytases by enhancing their stability at acidic pHs and reducing Pepsin's Accessibility to its cleavage sites. Appl. Environ. Microbiol. 2016, 82, 1004-1014. [CrossRef] [PubMed]

44. Niu, C.; Yang, P.; Huang, H.; Wang, Y.; Yao, B. Engineering of Yersinia Phytases to Improve Pepsin and Trypsin Resistance and Thermostability and Application Potential in the Food and Feed Industry. J. Agric. Food Chem. 2017. [CrossRef] [PubMed]

45. Tan, H.; Wu, X.; Xie, L.; Huang, Z. Identification and characterization of a mesophilic phytase highly resilient to high-temperatures from a fungus-garden associated metagenome. Appl. Microbiol. Biotechnol. 2015. [CrossRef]

46. Tan, H.; Miao, R.; Liu, T.; Cao, X.; Wu, X.; Xie, L.; Huang, Z.; Peng, W.; Gan, B. Enhancing the thermal resistance of a novel acidobacteria-derived phytase by engineering of disulfide bridges. J. Microbiol. Biotechnol. 2016, 26, 1717-1722. [CrossRef] [PubMed]

47. Ravindran, V. Feed enzymes: The science, practice, and metabolic realities. J. Appl. Poult. Res. 2013, 22, 628-636. [CrossRef] 
48. Zhou, S.; Liu, Z.; Xie, W.; Yu, Y.; Ning, C.; Yuan, M.; Mou, H. Improving catalytic efficiency and maximum activity at low $\mathrm{pH}$ of Aspergillus neoniger phytase using rational design. Int. J. Biol. Macromol. 2019, 131, 1117-1124. [CrossRef] [PubMed]

49. Bryan, D.D.; Classen, H.L. In Vitro Methods of Assessing Protein Quality for Poultry. Animals 2020, 10, 551. [CrossRef]

50. Niu, C.; Yang, P.; Luo, H.; Huang, H.; Wang, Y.; Yao, B. Engineering the residual side chains of HAP phytases to improve their pepsin resistance and catalytic efficiency. Sci. Rep. 2017, 7. [CrossRef]

(C) 2020 by the authors. Licensee MDPI, Basel, Switzerland. This article is an open access article distributed under the terms and conditions of the Creative Commons Attribution (CC BY) license (http://creativecommons.org/licenses/by/4.0/). 